\title{
Un sistema de validación documental: de la Quirografía a las cartas partidas ${ }^{1}$
}

\author{
Juan Carlos Galende Diaz
}

\section{INTRODUCCIÓN}

Etimológicamente, el término "quirógrafo" proviene de dos vocablos griegos, $\chi \varepsilon 1 \rho$ (mano) y $\gamma \rho \alpha \dot{\alpha} \varphi \varepsilon ı$ (escribir = escritura) ${ }^{2}$.

En Derecho Romano, en su acepción más amplia, se entiende por quirógrafo el documento emanado por un particular que estaba interesado en los acontecimientos relatados en el mismo. Más tarde se restringió esta acepción para significar un escrito preconstituido, facilitado por una de las dos partes, como un medio de prueba hacia la otra parte. De este modo, el quirógrafo aportaba una garantía en la que se hacia constar, por ejemplo, una obligación unilateral: un pago, una promesa, un préstamo, etc., y era sinónimo de instrumento: bien epístolar, bien "cautico".

Primitivamente, considerado como medio de prueba, el quirógrafo no tenía forma alguna particular para su validez, pero, los romanos, para evitar posibles dificultades venideras, utilizaron desde época temprana diversas precauciones. Así, el acta que indicaba los nombres del suscriptor y del acreedor al comienzo o en el cuerpo del texto se reforzaba con el sello de la parte respectiva y de los testigos, a quienes se denominaba "parariì. Posteriormente, un decreto senatorial publicado en tiempos de Nerón determinó la forma externa que debian tener determinados escritos ( «tabulae») en los que constaba un contrato o cualquier otro acto público o privado, debiendo de ser taladrados en el margen superior y en la parte cen-

\footnotetext{
- Agradezco al Dr. D. Ángel Riesco Terrero, catedrático de Paleografía y Diplomática de la U.C.M., la inestimable ayuda y colaboración prestada en la realización de este trabajo.

2 Según el Diccionario de Autoridades, por "chirographo" se entiende "la cédula u obligación firmada del deudor, sin intervención de escribano; es la obligación que tiene el acreedor con la firma del deudor". Diccionario de Autoridades, vol. I, Madrid, 1976, p. 323.
} 
tral, y luego atravesados por una triple atadura sobre la cual iban los sellos de los testigos, a fin de garantizar la conservación del escrito que custodiaba ${ }^{3}$. Será durante esta época cuando el contrato literal fue abandonándose y ya no se utilizaban escritos de prueba, quirógrafos ni "cautiones", tendiéndose en la práctica a identificarlas con los quirógrafos de los extranjeros, que eran contratos literales que tenian además de su prueba, su fuerza obligatoria en el escrito mismo, que se consideraba causa eficiente de aquella.

Por su parte, en Derecho Canónico se entiende por quirógrafo, el acta, firmada por el Papa, correspondiente a la bula consistorial, es decir, despachada en consistorio de cardenales.

Sobre este tema, Cencetti afirma que el «motu propio", despojado de una particular forma exterior, es el más tardío quirógrafo ${ }^{4}$. De esta manera, siguiendo a Battelli, califica como quirógrafos las láminas que este segundo autor presenta como tales en su conocida obra Acta Pontificum: la primera de Clemente VIII del año 1600 y la segunda de Clemente XIV del año 1769. En ambos documentos, los propios pontífices catalogan sus escritos como quirógrafos: "... Per tanto in virtù di questo nostro chirografo, qual vogliamo di nostra certa scientia et pienezza di potestà che habbi forza di Motu propio..." y "...E col presente nostro chirografo, il quale vogliamo che colla sola nostra sottoscrizione abbia tutto il valore, ancorché non presentato né registrato, vi liberiamo dal render conto di detta scatola e lettere, perché questa é la volontà nostra...", respectivamente ${ }^{5}$.

En Diplomática, por quirógrafo se identifica la voz con que se adjetivan los diplomas o documentos, por lo general, medievales, cuyo texto fue escrito más de una vez sobre una misma hoja de pergamino. El propio Jean Mabillon, en su obra De re dip/omatica libri sex, ya apuntó que el término "chirographum" se utilizaba desde el siglo xII para referirse en particular a

Un ejemplo de esta forma documental es el llamado "Tríptico de Blasendorff, fechado en el año 895. En él, estipula la venta de un esclavo joven, con garantía y recibo de la sexta parte del precio fijado, antes del nombre del vencedor («auctor") aparece el de un fiador («auctor secundus").

G. CenCETTI, Lineamenti di storia della scrittura latina, Bologna, 1954, p. 337

J. Battellu, Acta Pontificum, 2. a ed., Ciudad del Vaticano, 1965. Nos estamos refiriendo a la figura 43A, que corresponde a un quirógrafo de Clemente VIII del 14 de enero de 1600 para registrar la bula de investidura del reino de Nápoles a Felipe III, y a la 43B, perteneciente a otro del 26 de julio de 1769 de Clemente XIV a monseñor Garampi, prefecto del archivo italiano. Modelos de motupropios son ofrecidos por este autor en las láminas 36 (suplicación con fórmula "Motu propio" de Pablo III techada el 22 de febrero de 1539), 39B (motupropio de Pablo IV al cardenal Guido Ascanio del 21 de septiembre de 1557) y 47 (motupropio de Clemente XII datado el 25 de julio de 1735). 
las "cartas dentadas" ${ }^{6}$. Más tarde, los benedictinos René Prosper Tassin y Charles Toustain, identifican "chartes parties et dentelées" con el término "chirographa" y, además, emplean la acepción "cirographa" - sin hache - para referirse a la leyenda de separación que se coloca entre los documentos partidos ${ }^{7}$.

Si se trataba de un duplicado, uno de los textos se exteridía en la parte superior, mientras que debajo se repetía la copia. En el espacio comprendido entre ambos documentos se trazaba una línea divisoria (recta, ondulada, dentada, con leyendas, etc.), por donde se cortaba el pliego, de manera que la mitad superior de las letras insertadas quedaban en el primer escrito y la parte perteneciente al pie de las mismas, correspondía al segundo texto. Esta disposición es semejante a la documentación contemporánea cuya base es el talonario en que debe quedar la matriz, como por ejemplo es el caso de las acciones u obligaciones y de ciertos libros menores utilizados en el comercio, banca e industria.

Pero, ¿por qué se utilizó precisamente la palabra "c(h)irographum» en el corte? Como apunta $W$. Trusen, la respuesta a este interrogante sólo puede ser una hipótesis. El punto de partida es el dato de que, en ocasiones, se hacía referencia en las copias al propio medio probatorio del documento original recurriendo a escribir sobre la lista de "signa" la palabra «cyrographum» o alguna similar, como si se dijese: en este punto, en el original, viene la signatura. También podía ponerse esta palabra durante la toma de firmas, como indicación de que alli delante tuvo lugar sobre el original lo que tiene fuerza probatoria, la signatura o «firmatio». Quizá, puede explicarse con ello que precisamente esta palabra, localizada en el borde del documento, se partiera y utilizara como medio de certificación ${ }^{8}$.

\section{EVOLUCIÓN}

Los quirógrafos derivan de ciertos testimonios e informes antiquísimos, que serían como prueba en pleito y testificaciones, sin que en ellos se mencionase a los autores ${ }^{9}$. Su propia escritura constituia una

J. Mabillon, De re diplomatica libri sex, vol. I, cap. 2, Paris, 1709, p. 5.

7 R.P. TASSIN y CH. Toustaln, Nouveau traité de Diplomatique, vol. I, Paris, 1750, p. 358.

B W. TRUSEN, "Chirographum und Teilurkunde im Mittelalter", Archivalische Zeitschrift, 75 (1979), pp. 242-243.

9 H. BREsslau, Handbuch der urkundenlehre, Berlín, 1958, pp. 90-91. 
prueba de legitimidad, utilizándose ya en el mundo griego ${ }^{10}$ y luego en el romano ${ }^{11}$.

La fuerza probatoria residía en la escritura autógrafa, no en los testigos, ya que, en su origen, sólo tenía validez en contexto particulares, como medio para probar una deuda de préstamo o una «stipulatio". En esta época, tales escritos probatorios y testimoniales se fijaban sobre tablillas de cera (dípticos y trípticos) o planchas de metal. Por lo general, como ya hemos apuntado, no se citaba al autor, por ser él sólo quien tenia interés en la prueba. Muestras de estas fuentes documentales son tablillas pompeyanas, encontradas en 1875, que versan sobre asuntos de carácter administrativo. De acuerdo con Gaius III, 134, los peregrinos podian obligarse, de acuerdo con sus derechos, mediante "chirographa" y "syngraphae" ${ }^{12}$. Luego se observa una eliminación de estas restricciones.

De estos testimonios escritos derivaron otros, similares en su forma, que fueron ganando terreno desde el siglo III, por ser más seguros en cuanto a prueba. Es a estos nuevos documentos a los que se les denominó "chirografos" "13. La fuerza probatoria estribaba en la autografía, pero sólo adquirian valor pleno cuando los testigos lo confirmaban. Respecto a su redacción, no siempre eran autógrafos. Si eran los propios interesados los encargados de escribirlos se redactaban en forma subjetiva, mientras que si eran terceras personas solían hacerse en forma objetiva. Pensemos que, en ocasiones, por inhabilidad del autor: ceguera, manquera, analfabetismo, ancianidad, etc., el escribiente era una delegado directo suyo. Normalmente, en ellos se cita a los amanuenses.

Desde el siglo III, el antiguo Derecho Romano otorgaba validez a cartas con contenido dispositivo. La forma de los documentos quirografiados era apropiada por esta finalidad: su mandato o disposición. También se autorizaron en forma de carta o «litterae» (donación, venta, etc.), pero siempre con el objetivo expuesto.

El documento testimonial romano antiguo, sin sello, se fusiona con el quirógrafo al incorporar la firma de la persona que se obliga.

10 Véase H. Burnickel, Das Chirographum im ptolemäischen Recht, Diss. iur., Erlangen, 1950.

"El concepto de "chirographum" fue tomado del mundo helenístico por los romanos, tanto en su acepción general de autógrato, como en el sentido jurídico estricto, es decir, como tipo particular de documento que exigia el punto y letra en la declaración, subjetivamente extendida, de! implicado, o en la signatura. B. BISCHOFF, "Zur frühgeschicht des mittelalterlichen chirographum", Archivalische Zeitchrift, 50-51 (1955), pp. 297-300.

12 W. Trusen, op. cit., p. 234.

13 C. PAOLI, Diplomática, Firenze, 1942, p. 19. 
Con el Corpus luris Civilis del siglo vi, Justiniano alcanzó su más grande e imperecedera fama. Está compuesto por: 1) el "Codex", publicado en el 528-529 y en el que se compilaron las constituciones imperiales o estatutos entonces vigentes, anulándose su valor según una provisión general; 2) el "Digesto" o las "Pandectae", tratado del año 533-534 en el que se reúnen y armonizan los comentarios y escritos de los juristas; 3) la "Instituta", tratado sistemático y elemental de jurisprudencia, del mismo año que el "Digesto", que sirvió de introducción a su obra principal; y 4) las "Novellae Constitutiones", serie de correcciones y reformas publicadas en el año 535.

En el Cuerpo del Derecho Civil Romano se encuentran diversas normas sobre los quirógrafos. Así, en el "Código" ${ }^{14}$, de una manera directa, se refiere a ellos en el apartado 20 del título XXI («De la fe de los instrumentos y de la pérdida de los mismos, de las épocas que han de hacerse, y de lo que se puede hacer sin escritura") del libro IV, por el que se prohibe hacer cotejos de letras sobre quirógrafos que no tuviesen, al menos, las firmas de tres testigos:

"Comparationes literarum ex chirographis fieri et aliis instrumentis, quae non sunt publice confecta, satis abundeque occasionem criminis falsitatis dare et in indiciis et in contractibus, manifestum est. Ideoque sancimus, non licere comparationes literarum ex chirographis fieri, nisi trium testium habuerint subscriptiones, et prius literis eorum ficies imponatur vel ipsis hoc depenentibus (sive cunctis, sive omnimodo duobus ex his), sive comparatione literarum testium procedente. Et tunc ex huiusmodi chartula iam probata comparatio efficiatur. Aliter etenim fieri comparationem nullo concedimus modo, licet in semetipsum aliquis chartam conscriptam proferat, sed tamtummodo vel ex forcusibus vel publicis instrumentis, vel ex huiusmodi chirographis, quae enumeravimus, comparationem trutinandam. Omnes autem comparationes non aliter fieri concedimus, nisi iuramento antea praestito ab his, qui comparationem faciunt, fuerit affirmatum, quod neque lucri causa, neque inimicitiis, neque gratia tenti huiusmodi faciunt comparationem. Et hoc observari tam in omnibus sacris nostris scrinis, quam in apparitione omnis sublimissimae praefecturae nec non magisteriae potestatis, ceterisque omnibus iudiciis, quae in orbe nostro constituta sunt, his omnibus in posterum observandis. Comparationes etenim iam antea factas retractari, extra periculum minime est. Dat. XIV Kal. april." ${ }^{15}$

En el título XXIII del libro VI, dedicado a los testamentos, en su apartado 21, se legisla que únicamente sea válido aquel testamento escrito a mano que lleve las firmas y sellos de los testigos:

14 Cuerpo del Derecho Civil Romano: Código, 2 tomos, Valladolid, 1988 (ed. L. Garcia CORRAL).

${ }_{15}$ El emperador Justiniano a Juliano, prefecto del pretorio en el año 530. Ibid., tomo I, pp. $452-453$. 
"Hac consultissima lege sancimus, licere per scripturam conficientibus testamentum, si nullum scire volunt quae in eo scripta sunt, signatam vel ligatam, vel tantum clausam involutamque proferre scripturam, vel ipsius testatoris vel cuius libetalterius manu conscriptam, eamque rogatis testibus, septem numero, civibus romanis puberibus, omnibus simul offerre signandam et subscribendam, dum tamen testibus praesentibus testator suum esse testamentum dixerit, quod offertur, eique ipse coram testibus sua manu in reliqua parte testamenti subscripserit; quo facto, et testibus uno eodem die ac tempore subscribentibus et consignantibus, testamentum valere, nec ideo infirmari, quod testes nesciant, quae in eo scripta sunt testamento... Quod literas testator ignoret vel subscribere nequeat, octavo subscriptore pro eo adhibito eadem servari decernimus... Finem autem testamenti subscriptiones et signacula testium esse decernimus. Non subscriptum namque a testibus ac signatum testamentum pro imperfecto haveri convenit... Dat. prid. Id. Septemb. Constantinop." ${ }^{16}$

Justiniano, en el año 530, comunica al prefecto Julián que si alguno hubiere escrito, de su propio puño, un testamento o codicilo, y así lo hubiese hecho constar en la escritura, sería suficiente, siempre que sea firmado por los testigos:

"... sancimus, si quis sua manu totum testamentum ve! codicillum conscripserit, et hoc specialiter in scriptura reposuerit, quod haec sua manu confecit, sufficiat ei totius testamenti scriptura, et non alia subscriptio requiratur neque ab eo, neque pro eo ab alio, sed sequantur huiusmodi scripturam et $\mathrm{li}$ terae testium et omnis, quae exspectatur, observatio, et sit testamentum validum, et codicillus, si quinque testium literae testatoris scripturae coadunentur, in sua firmitate remaneat, et nemo callidus machinator hiuismodi iniquitatis in posterum inveniatur. Dat. VI. Kal. April. Constantinop.» 17

En el título XXVII del libro VIII se recoge una constitución del emperador Gordiano a Festo del año 239, por la que también se obliga prenda por causa de crédito quirográfico:

"Pignus intercidit, si novatione facta in alium ius obligationis transtulisti nec, ut ea res pignoris nomine teneretur, cautum est. Quodsi pactum inter te eumque, qui postea dominus fundi constitutus novam obligationem susceperat, intercessit, ut idem fundus tibi pignoris nomine teneatur, quamvis personali actione expertus feceris condemnationem, pignoris tamen habes persecutionem. Ac si in possessione fueris constitutus, nisi ea quoque pecunia tibi a debitore reddatur vel offeratur, quae sine pignore debetur, eam restituere propter exceptionem doli mali non cogeris. lure enim contendis, debitores

I6 Los emperadores Teodosio y Valentiniano a Florencio, prefecto del pretorio en el año 439. Ibid., tomo II, pp. 58-59.

17 Libro VI, título XXIII, apartado 28. Ibid., tomo II, pp. 61-63. 
eam solam pecuniam, cuius nomine pignora obligaverunt, offerentes audiri non oportere, nisi pro illa etiam satisfecerint, quam mutuam simpliciter acceperunt. Quod in secundo creditore locum non habet; nec enim necessitas ei imponitur chirographarium etiam deditum priori creditori offerre" ${ }^{18}$.

En lo referente a «cosas litigiosas» —título XXXVII, del libro VIII- los emperadores Graciano, Valentiniano y Teodosio expiden en el año 380, al prefecto Taciano, una constitución por la que se establece que si cualquier persona hubiera, por ejemplo, legado un testamento, una cosa litigiosa, un quirógrafo dudoso o dejado una herencia, no tenga el fisco ni otra persona facultad para litigar, sino que se haga la estimación de este litigio, la cual se habrá de pagar a quienes se dejaron las acciones o las cosas litigiosas:

"Quincunque rem litigiosam, vel ambiguum chirographum, quodlibet denique mobile vel immobile fisco nostro vel potentiori seu aliis personis in testamento sive codicilo legaverit fideive commiserit aut per hereditatem reliquerit, nullam fiscus noster vel alia persona licentiam habeat iurgiorum, nec iudicium subeat, sed aestimatio eius litis ineatur, praestanda his, quibus actiones vel res litigiosae relictae sunt. Eandem litem ipsi heredes peragant, suarum actionum periculo ea, quae litigiosa fuerant relicta, vindicantes. Quod et de chirographis placet, ut heredes relictorum fisco vel aliis personis praesentem pecuniam numerent, et iudicio eos quos obnoxios existimant, persequantur. Dat. XV. Kal. Iul. Thessalonica". ${ }^{19}$

El título XXIII del libro IX: «De los que ellos mismos se escriben en un testamento", recoge dos disposiciones relativas a los quirógrafos. En el apartado número 4, el emperador Alejandro remite una disposición a Crescente el año 225, por la que los legados que de su propia mano hubiere escrito para sí el marido en el testamento de su mujer, son considerados nulos:

"Quae in testamento uxoris maritus sua manu legata sibi adscripserit, pro non scriptis habentur, et legis Corneliae poena, si venia impetrata non est, locum habet. PP. III. Non. Februar». ${ }^{20}$

En el número 6, los emperadores Diocleciano y Maximiano envían una norma a Aufidio en el año 290, referente a los quirógrafos escritos por el propio esclavo, por orden de su señor, en favor de su libertad:

18 Ibid., tomo II, p. 343.

19 Fue dada nuevamente en Constantinopla, bajo el consulado de Pompeyo y de Avieno, el año 501 . Ibid., tomo II, p. 355.

${ }_{20}$ ibid., tomo II, p. 466. 
"Si libertatem tibi manu tua, imperante domino, adscripsisti, quum proponas, dominum non subscripsisse nec suis literis tuam libertatem expressim agnovisse, ad impetrandam libertatem senatusconsulti auctoritas tibi obest. Poena tamen falsi tibi remittitur, quoniam non potueras contra domini voluntatem venire. PP. VI. Id. Decemb. ${ }^{21}$

Del mismo modo, en diversas disposiciones del «Código» se hacen referencias más directas a los quirógrafos, siempre con la cláusula de que los testigos tenían que confirrnar su contenido. Así se puede comprobar en el título XXIII del libro I: «De las diversas clases de rescriptos y pragmáticas sanciones", en el título LVI del libro II: "De los recibidos como árbitros", en el título XX del libro IV: “De los testigos", en el título XXI del libro IV: «De la fe de los instrumentos y de la pérdida de los mismos, de las épocas que han de hacerse, $y$ de lo que se puede hacer sin escritura", en el título XXIII del libro VI: «De los testamentos y de cómo se otorgan los testamentos", en el título XXXII del libro VI: "De qué modo se abren, se inspeccionan y se copian los testamentos", en el título XXXVII del libro VIII: «De las cosas litigiosas", en el título XXII del libro IX: «Sobre la ley Cornelia relativa a las falsedades», y en el título XXIII del libro IX: "De los que ellos mismos se escriben en un testamento".

En las "Novelas" 22 se alude al tema de la quirografía en la constitución LVIII: "De los que interponen apelación, y de cuándo se hará cotejo de letras mediante escritura de propia mano, del juramento de dilación, y de que se añada al juramento de calumnia». En su capítulo II, Justiniano, el año 537, prescribe que, si alguien lo solicita, se extienda a la documentación autógrafa privada lo relativo al cotejo de la pública:

"... Quia enim dudum scripsimus legem, volentem ex propriae manus scriptura nullam fieri comparationem, sed ex solis documentis publice celebratis, videmus autem causarum experimentum egere competenti correctione in lege, et hoc ex ipso litigantium invenimus experimento, emendare eam secundum hoc voiumus schema. Crebro namque proferens quidam cuiusdam manus documentum, et ex eo faciens aut conventionem, aut suarum allegationum probationem, quum eiusdem manus adversa pars protulisset litteras, et legitimam probationem exinde vellet fieri, ex quibus ipse adversarius illud obtulerat, ille utebatur lege, quia oporteret ex publice confectis documentis fieri comparationem, et non ex aliis, quae a quoquam scribuntur. Sancimus, si quando aliquid tale contigerit, et quispiam voluerit secundum eas, quae ab adversario prolatae sunt, litteras fieri examinationem, non accusetur hoc tamquam non recte sit factum. Cui enim ipse credidit, et quod protulit is, con-

22 Cuerpo del Derecho Civil Romano: Novelas, Valladolid, 1988 (ed. L. García CORRAL). 
tra quem et ex quo suas affirmat allegationes, hoc non accuset, neque prohibeat comparationem litterarum ad eum fieri, licet contingat esse documentum manu cuiuscunque conscriptum. Neque enim ipse sibi resistet, et quae affirmavit, hace accusabit. Si vero etiam ex publicis archivis proferatur chara, velut desuscepto mensae gloriosissimorum praefectorum (novimus enim etiam aliquid tale quaesitum), et quod ex publicis profertur, et publicum habet testimonium, etiam susceptibile hoc esse ad colletiones manuum ponimus. Ubique enim falsitatis peccatum odio haberites, et iusiurandum praebere discutientes exhibitas litteras sancivimus, et ex publicis solummodo documentis comparationem fieri permisimus. Quapropter valeat per omnia lex illa praesente subdivisione delata ei, iureiurando tamen comparantium modis omnibus praebendo. Dat. XV. Kal. Septemb. Constantinop." ${ }^{23}$

También se encuentran párrafos relativos a los quirógrafos en la constitución LXXVI: "De la seguridad y fe de los instrumentos, y en primer lugar del depósito, del mutuo, y de otros documentos escritos, a la verdad, privadamente, teniendo o no teniendo testigos; de los instrumentos hechos públicamente; de los cotejos de escritura de propia mano; de los instrumentos expuestos por personas que no saben, o saben poco, de letras; de los contratos no escritos; de los contratos hasta la cuantía de una libra de oro; de los contratos que se hacen en los campos, y de que la ley tenga aplicación en los documentos y contratos futuros", en la que Justiniano, el año 538, legisla lo siguiente en relación a la autografía y a la importancia que adquieren los testigos como elementos que contribuyen a mayor fiabilidad:

"... Si quis igitur vult caute deponere, non soli credat accipientis scripturae, sed is, qui depositum dat, advocet etiam testes ut possibile est honestos et fide dignos, et non minus tribus, ut non in sola scriptura et eius examinatione pendeamus, sed sit iudicantibus etiam testium solatium... Sed et si quis aut mutui instrumentum, aut alterius cuiuspiam faciat, et noluerit hoc in publico conficere, quod et in deposito definivimus, non ex ipso videatur credibile, quod scribitur super mutuo documentum, nisi etiam testium habeat praesentiam fide dignorum non minus trium, ut, sive veniant et propriis subscriptionibus attestentur, sive alii quidam testificentur, quia praesentibus eis confectum est documentum, fidem causa ex utroque percipiat, etiam litterarum examinatione penitus non repulsa, sed sola non sufficente, augmento autem testium confirmanda... Si tamen quisquam aut doponens, aut mutuans, aut aliter contrahens contentus sit scriptura sola eius, cum quo contrahit, in ipso erit, ut sciat, quia in illius fide totum ipse suspendit. Et quidem quantum ex scriptura, non sufficiens videbitur fides, nisi secundum nostram legem addiciatur documento credulitas aut praesentia testium, coram quibus contractus est factus, aut forsan novissimum eius rei refugium inve-

23 lbid., pp. 214-218. 
nerit, dicimus autem quod ex iureiurando est. Nam non infirmamus quod factum est; nam falsitates et imitationes metuentes, et nudis eis exsistentibus non credentes huiusmodi subtilitatem causae addimus, non ut credentes privemus fide sue circa micos, sed ut, quantum possibile est, et perfidiam et negationem multis reconvincamus modis... Sed et si instrumenta publice confecta sint, licet tabellionum habeant supplementum, adiciatur et eis, antequam compleantur, sicut dictum est, testium ex scripto praesentia... Oportet autem iudicantes, et si qua signa invenerit adscripta chartis, etiam haec requirere et legere niti (plurima namque novimus et ex illis apparuisse), et non facile fidem litterarum $\epsilon x$ aliarum collatione recipere, propter dudum dictas a nobis causas... Oportet vero in iis, qui litteras nesciunt, et testes et omnino tabularios adhiberi, in quibus locis sunt tabularii, maxime autem testes non ignotos contrahentibus, ut quidam scribant pro illiterato aut paucas litteras sciente, alii vero attestentur, quia etiam praesentibus eis haec gesta sunt, et scierunt eum, et ita talium instrumentorum suscipiatur fides; manifestum exsistens, quia non minus, quam quinque testes in his talibus adhibendi sunt, inter quos erit et qui scribit pro contrahente aut totum, aut quae post paucas litteras illius posita sunt, quatenus nihil omittatur de summa subtilitate... Haec autem omnia tenere in civitatibus volumus; nam in agris, ubi multa simplicitas est, et neque scribentium aut testium multorum copia est, quae hactenus apud eos valuerunt et nunc sint firma... Dat. prid. Non. lud. Constant». ${ }^{24}$

Por su parte, en los cuatro libros de la "Instituta» ${ }^{25}$ apenas hay referencias a los documentos quirográficos, aunque en los títulos $X, X I$ y $X I I$ del libro segundo - relativos al testamento-, y en los títulos $X X, X X I$, XXII, XXIII y XXIV del tercero - referentes a las obligaciones, compraventas $y$ arrendamientos--, se insiste en la importancia que adquieren los testigos en la validación documental.

En los 50 libros del "Digesto" ${ }^{26}$ tampoco aparecen alusiones directas a los quirógrafos. De todas las maneras, en diferentes títulos de ciertos libros, como acontecía en la "Instituta", se realizan observaciones sobre el tema de la validación documental, perseverando en los mismos puntos reseñados. Así se puede observar en los títulos IV y $\vee$ del libro XXII ( De la fe de los instrumentos y de la pérdida de los mismos» y "De los testigos", respectivamente), en los títulos I, III y IV del libro XXVIII, títulos III y IV del libro $X X I X$, título I del libro XXXV, título II del libro XXVII y el título IV del libro XL (todos ellos relativos a diversas circunstancias referentes a los testamentos, tales como la forma de realizarse, transcribirse, abrirse, validarse, etc.).

\footnotetext{
24 lbid., pp. 268-272.

25 Cuerpo del Derecho Civil Romano: Instituta-Digesto, 2 tomos, Valladolid, 1988 (ed. L. Garcia Corral).

${ }_{26}$ Cuerpo del Derecho Civil Romano: Instituta-Digesto, 2 tomos, Valladolid, 1988 (ed. L. Garcia Corral).
} 
Es decir, en el "Corpus Justinianus" el quirógrafo se encuentra tanto en el sentido de signatura o firma legalmente vinculante, como en el de "cautio privatorum», obligación, pagaré y factura autógrafa. El "chirographum" era un documento legalmente vinculante, redactado en forma subjetiva, que podía estar escrito de puño y letra o bien firmado o signado.

Asimismo, el emperador bizantino León VI (866-912), en sus «Novellae Constitutiones" ${ }^{27}$, mantiene las mismas premisas que las expuestas anteriormente sobre la validación de la documentación, es decir, la importancia que adquieren los testigos. Así se puede comprobar en todos aquellos capítulos referentes a este tema; por ejemplo, el XLI: "Que para la fe de los testamentos basten en las ciudades cinco testigos y tres en viajes y en el campo", el XLII: "Que el suficiente número de testigos haga válidos el testamento, aunque éste no tenga ni las firmas ni los sellos de aquellos", el L: "La donación, cuya estimación no supera la de quinientos áureos, aunque no haya sido escrita, habiendo sido confirmada con tres testigos, es juzgada válida, y examinadas en esta forma las donaciones deben o valer, o ser invalidadas" y el LXIX: "De la testificación de los ciegos, de los que no saben de letras, y de las mujeres":

"... nec enim in solo scriba illorum fidem niti vult... etiam annectimus, ut, si quando, ad sui confirmationem (quod frequenter incidit) iuramentis testamento opus sit, ipsi etiam, qui testamentum conscripserunt, una cum iuraturis testibus rei fidem et veritatem corroborent" ${ }^{28}$.

Además de las fuentes de derecho romano, la Biblia también se convirtió, con la cristianización de los pueblos paganos, en fuente de difusión del concepto "chirographum». Esta expresión se encuentra repetidas veces en el libro de Tobías, donde el "pagaré" que éste recibe de Gabelus es librado al final por el ángel Rafael ${ }^{29}$. Una cita adicional, más efectiva, se encuentra en la Epístola de San Pablo a los Colonenses: "delens quod adversus nos erat chirographum decreti" "30, la cual fue sometida a exégesis con bastante frecuencia, con lo que se contribuyó de forma considerable a la difusión del concepto, incluso cuando no mediaba una conexión directa con el derecho romano. Entre otros autores, en calidad de «obligación», es tratado por Hipólito, Ireneo, Orígenes, Tertuliano,

${ }^{27}$ León VI, llamado el Sabio o el Filósofo, dictó desde el año 887 al 891 ciento trece "Novelas", que fueron recogidas en una colección, por lo que este emperador bizantino es considerado el "Justiniano de Oriente».

28 Cuerpo del Derecho Civil Romano: Novelas, pp. 663-664.

29 Tobias, 1,$17 ; 4,21 ; 4,22 ; 5,3 ; 9,3 ;$ y 9,6 .

30 Epistola de San Pablo a los Colonenses, 2, 14. 
Orosio, Cirilo de Jerusalén, Hilario de Poitiers, San Ambrosio, Ambrosiastro, San Jerónimo, Rufino de Aquileia y San Agustín; en territorio galo, se pueden citar Euquerio de Lyon, Fausto de Riez y Cesáreo de Arlés ${ }^{31}$. Por consiguiente, no puede ignorarse la influencia bíblica en el empleo del concepto "chirographum» 32.

Hasta el siglo XI, el término «quirographum» fue genérico, pero al igual que sucedió con el de "testamentum", luego fue cambiando de significado, restringiéndose. De esta manera, se entendió por tal, aquel documento con una forma especial redactado con duplicación de texto sobre un mismo folio de pergamino ${ }^{33}$, validados con una divisa común que se coloca en la mitad hasta separar los distintos documentos. Las actas a las que se dio este formato y disposición se hacen corrientes a comienzos del siglo xil y crecen durante los dos siguientes. De todas las maneras, no se sabe a ciencia cierta la fecha en que nace el documento partido con inserción de la palabra "chirographum", aunque parece haber surgido hacia la mitad del siglo $\mathrm{x}$.

Esta disposición especial se produce para escribir originales múltiples (dos o más) sobre un mismo folio, aunque puede sospecharse que este nuevo tipo de certificación se limitó inicialmente a las copias, y más concretamente a las "copias auténticas". Mientras que los originales poseian una "fides publica" de fundamento religioso, las copias de aquel tiempo no tenían ninguna forma satisfactoria de acreditación. De ahí, por tanto, la primera aplicación del nuevo método, a fin de obtener seguridad. Su comparación podía justificar su respectiva autenticidad. Es difícil determinar con precisión el momento en que empezaron a utilizarse, aunque en épocas merovingias se mencionan numerosos originales múltiples de cartas de un mismo tenor ("chartae paricolae eodem tenore conscriptae») remitidas a las partes interesadas ${ }^{34}$. Bautier ${ }^{35}$ puntualiza que esta forma llega a Francia en el siglo $x^{36}$ desde Irlanda, donde se conocia ya en el sigo Vil, y

31 W. TRusen, op. cit., pp. 235-236.

32 Autores como W. LEVISON, pretenden explicar la frecuente utilización del término "chirographum" entre los anglosajones partiendo del lenguaje biblico, W. LEVISON, England and the continent in the eighth century, Oxford, 1946, p. 232.

33 Cada uno de estos ejemplos era llamado quirógrafo. Vocabulaire International de la Diplomatique, Valencia, 1994 , p. 30 (ed. M.`M. CARCEL OATI).

34 Según Paoli, esta forma documental surge en Inglaterra durante el siglo $1 \times$ (año 895). En Alemania la carta partida más antigua que se conserva es del siglo $\times$ (año 967), en Francia del $\times 1$ (reinado de Enrique I) y en italia del XII (año 1174). C. PAOLI, op. cit., p. 50.

35 R. H. BAutieR, "L'authentification des actes privés dans la France Medievales", Notariado público y documento privado: de los origenes al siglo XIV, I, Valencia, 1989, pp. 710-711.

36 El tema de la difusión de los quirógrafos en Francia y su forma material ha sido el objeto de 
desde los países anglosajones. A partir de los primeros capetos, la misma cancillería real recurre a ellas, siendo ejemplo diversos diplomas de Enrique I. Va a ser un sistema muy empleado en todo el territorio francés; quizá sea en los territorios del norte en donde menos se usa, aunque desde el siglo XII se hace más frecuente. Desde el siglo XIII y comienzos del XIV, en el suroeste francés se utiliza para dar más credibilidad a las actas notariales, además de la forma del quirógrafo, el sellado del mismo ${ }^{37}$.

El documento anglosajón, como en el quirógrafo tardorromano -que fue su modelo-, se remata con las firmas de los otorgantes o testigos, y más concretamente, sus signaturas, que consisten, por lo general, en una cruz. Además, se encuentran las fórmulas: "pro contirmatione subscripsi», "propria manu subscripsi», "propria manu crucem infixi, signum santae crucis scribendo firmavi», "consensi et subscripsi», etc. De esto, se puede inferir que la autografía podía consistir en una "firmatio" mediante contacto con la cruz. Se manifiesta claramente que la fuerza probatoria del documento residía en este acto. El primitivo documento anglosajón no tenía un sello como elemento certificador, ni siquiera en los documentos reales. Se echaba en falta la forma de documento de tabelión, que comenzó a utilizarse en el continente. Tampoco existía la nota del escribano ${ }^{38}$.

De particular interés es el hecho de que con ello se adoptó tanto la forma del quirógrafo, como su propia denominación. Según advierte Winfred Trusen, en uno de los primeros documentos considerados auténticos: donación hecha en el año 681 por Aethelred, rey de Mercia, al abad de Malmesbury, aparece la siguiente fórmula: "scripta est autem hec cirographi cartula" ${ }^{39}$. A partir de este momento se encuentra en numerosas escrituras, sobre todo como denominación del documento, pero ocasionalmente también refiriéndose a la signatura con el «signum crucis».

La relación con la tradición tardo-antigua se atestigua también por otras calificaciones de documentos. Por ejemplo, aunque con menor frecuen-

estudio en el artículo de M. PARISSE, "Remarques sur les chirographes et les chartes-parties antérieures à 1120 et conservées en France", Archiv für Diplomatik, 32 (1986), pp. 546-567. Se puede consultar también el estudio de A. PHILIPPE, cLes chartes parties des Archives départamentales des Vosges", Bulletin philologique et historique, (1921), pp. 151-199.

37 R. H. Bautier, op. cit., I, pp. 711-712.

so W. TRUSEN, op. cit., p. 236.

$39 \quad$ Ibid., p. 237. 
cia, se encuentra el término «cautio» ${ }^{40}$. La razón es que la «cautio» se redactaba bajo la forma de "chirographum", conexión que también se da en la compilación justiniana. En Irlanda, por su parte, la noción de "cautio" delata también una reminiscencia de la antigüedad tardia romana.

Con más frecuencia ha sido denominado el documento anglosajón, en sí, como "syngrapha». En la antigüedad tardía se hizo uso de este concepto para la expedición por partida doble de un quirógrafo a ambas partes, una "conscriptio", puesto que no se emplearon apenas los documentos suscritos en forma objetiva desde la segunda mitad del siglo cuarto. Puede considerarse, con seguridad, que el uso de esta palabra técnica con el sentido genérico de "chirographum» tenía también su modelo en la tradición tardorromana. «Syngrapha» podía, sin duda, usarse también como sinónimo de "chirographum» ${ }^{41}$.

Como manifiesta Giry ${ }^{42}$, mediante estas cartas se redactaron actas y contratos de todo tipo: avenencias, sentencias, privilegios, etc., pero especialmente contratos sinalagmáticos, como cambios, ventas, permutas, etc.

Preferentemente, en el lema o divisa se suele poner el término «cirographum", bien solo o acompañado de otros vocablos que especifican el carácter del acta: "cirographum memoriale", "cirographum commune", "cirographum manuscriptum", "cirographum pacis", "cirographum de molendino", etc. "3. Por ello, el significado de quirógrafo se va restringiendo poco a poco, tendiendo a representar cartas expedidas de forma múltiple, las cuales son comunes desde la centuria decimosegunda. Lema o división que puede ocupar tanto el borde superior, como el inferior o los laterales $y$, en ocasiones, varios a la vez.

A estas cartas se las designa "chartae partitae" o "divisae" (en Inglaterra "charta cyrographata" y en Francia "chartes parties"). En su zona de división, además de lo expuesto antes, también pueden apare-

40 En Derecho Romano se entendía con ello no sólo la declaración escrita de una deuda vigente, sino también la del acreedor referente a una deuda liquidada. Una mención simultánea de "chirographum" y "cautio" se puede encontrar en San Isidoro de Sevilla -Etimologias, 1. V, cap. 24-y en diversos glosarios medievales.

${ }^{4}$ W. TRUSEN expone una amplia relación de los primeros documentos validados por este sistema en territorio inglés. W. TRUSEN, op. cit., pp. 243-246.

42 A. GIRY, Manuel de diplomatique, New York, 1972, p. 511.

43 En sentido tradicional, son numerosos los autores que hicieron uso del término "chirographum". Entre ellos, baste citar a Alcuino, Haimo, Sedulio Escoto, Herveus de Bourg, Pedro Lombardo, Robert de Melun, Alejandro de Hales, Alberto Magno, Tomás de Aquino, Buenaventura, Richard Middleton, etc. 
cer otras leyendas, relativas a nombres de ciertos santos ( Sanctus Leo papa», "Sanctus Goericus episcopus", etc.), fórmulas piadosas ("In nomine Domini nostri», "Pacem habete inter vos", "Pax hominibus bone voluntatis", "Justus Dominus et Justicias», etc.), locuciones varias ("Datum optimum et omne bonum", "Cirographum et contestatio presentis kartae", etc.) y algunas veces hasta un dibujo (como un crucifijo). Pero la divisa más frecuente, particularmente desde el sur de Francia, la constituye una serie de letras del alfabeto (sólo algunas o el abecedario completo); de aquí el nombre de "littera per alphabetum divisa" y, en provenzal, "carta partita per $A B C$ " 44 , acepción más común de estas cartas. Letras que pueden ser mayúsculas, minúsculas o una combinación de las dos; y estar escritas con tinta roja, negra o de ambos colores.

Desde el siglo xill se brisa el corte en forma de sierra, sobre todo en Inglaterra ${ }^{45}$, en consecuencia, se conoce a este tipo de cartas partidas con el nombre de "chartae indentatae" y "chartae indenturae" (en francés "endentures"). A veces el corte se realiza adoptando formas onduladas, recibiendo entonces el nombre de "charta ondulata".

Aunque en el siglo $x v$ el número de estas actas había disminuido y se habia restringido su empleo para contratos de carácter privado, perduran hasta finales del antiguo régimen. Por ejemplo, en ciertas regiones francesas se localizan estos documentos hasta el año $1795^{46}$.

La jurisprudencia de la Edad Media se ocupó a fondo del quirógrafo en el contexto de los documentos privados, inicialmente en las glosas a los pasajes mencionados en lo que más tarde se denominaria Corpus luris Civilis, pero luego también de forma independiente en el Derecho Civil y Canónico. Bases que se usarían hasta bien entrada la Edad Moderna, escribiéndose sobre ellas trabajos especializados, como los de Martin Schele y Nicolaus Hontheim, de quien proviene esta conocida definición de quirógrafo: "chirographum est scriptura privata manu cuiusque subscripta et subsignata... generale nomen est et ad omnes cautiones pertinet... Proprie vero dicitur scriptura, qua se debere scripsit" ${ }^{47}$.

Por otra parte, en los léxicos de los siglos XVII y siguiente define al quirógrafo como: "privata scriptura seu cautio, manu alicuis subscripta vel

44 A. GIRY, op. cit., p. 512.

45 En Francia prevalece, generalmente, la división rectilinea. A. DE BOUARD, Manuel de Diplomatique, París, 1929, p. 366.

46 A. GIRY, op. cit., p. 513.

47 M. SCHELE, De chirographum, Basel, 1643. N. HontheIm, De syntaxi et fide instrumentorum, Mainz, 1607, p. 598. 
subnotata» ${ }^{48}$ o "contrato escrito, a través del cual alguien reconoce que ha recibido un préstamo" 49.

Posteriormente, se puede argumentar, que estos documentos son el origen del sistema, tan extendido en épocas contemporáneas, de los registros matriz.

\section{DESARROLLO EN LA PENÍNSULA IBÉRICA}

Características semejantes son las que adopta este sistema de validación en la Península Ibérica. Después de la dominación romana, la presencia de documentación quirografiada sigue siendo patente. Muestra de ello es la donación otorgada por el diácono Vicente en favor del monasterio de Asán el 29 de septiembre de año 551: "Domno sancto hac beatissimo et mihi speciali domno Victoriano abbati, Vincentius diaconus. Sancti nos Evangelii vox admonet dicens... Stipulans itaque stipulatus sum et spopondi Aquiliae legis mentione subnixa que scripturis omnibus solidum prestat robur. Quam cartulam manu mea propria scripsi, cui si gesta aut testes forsitan adhibiti non fuerint ologrife manus mee ad integrum conscriptio pro omni firmitate subsistit. Facta cartula in monasterio assani sub die $11{ }^{\circ}$ kalendas actobris anno $1{ }^{\circ}$ domini nostri Agile regis» ${ }^{50}$.

La fe pública de estas escrituras, por lo general realizadas entre particulares, se basaba en la identificación de la letra y en la presencia de testigos, correspondiendo a obispos y jueces dirimir dudas o confirmar la autenticidad ${ }^{51}$.

Junto a la "scriptura", medio de prueba tradicional, se emplearon otras modalidades comprobativas, como las cartas partidas, que si bien aparecen a finales del siglo ${ }^{52}$, no se hacen frecuentes hasta la centuria deci-

48 J. KAHL, Magnum Lexikon luridicum, Genf., 1689, p. 179.

49 C. S. SCHMIo. Gazophilacium politico-iuridicum et theoretico-practicum, Leipzig-Frankfurt, 1736, p. 124. Manuale vocabulorum, Würzburg, 1736, p. 136. A. BESold, Thesaurus Practicus, vol: I, 1740, p. 162

so A. Durán, Colección diplomática de la Catedral de Huesca, vol. I, Zaragoza, 1969, pp. 17-19.

51 A. CANELLAS, "El notariado en España hasta el siglo xIV: estado de la cuestión", Notariado público y documento privado: de los origenes al siglo XIV, I, p. 101.

52 Asi se puede atestiguar por diferente documentación de esta época. Entre ella, traemos la donación realizada el 27 de enero del año 979 por Revel al obispo de León Sisnando de la mitad de una viña situada en la villa de Maudes y que se conserva en el archivo de la catedral de León (original $n .^{\circ} 1341$ ), en la que el pergamino contiene dos documentos, redactados en sentido opuesto, sobre el mismo (E. SAEZ y C. SAEZ, Colección documental del Archivo de la Catedral de León (935985), vol. II, León, 1990, pp. 266-268), y la donación otorgada el 13 de febrero del 997 por Quiliolfo 
mosegunda en todos los reinos hispánicos ${ }^{53}$. Su declive empieza en la segunda mitad del siglo xIII con la multiplicación del uso del sello y la extensión del documento notarial auténtico, aunque pueden encontrarse, debido a su raigambre histórica, en diversos convenios del siglo $x \mathrm{~V}$, en cuyo anuncio de validación se menciona el sistema de carta partida por ABC: «E desto nos, las dichas partes, mandamos fazer dos cartas, amas partydas por a be ce, porque cada una de nos tenga la suya para guarda de su derecho" ${ }^{54}$. Incluso, a finales de esta centuria, se siguen expidiendo cartas con estas características, por ejemplo, la escrita por Rafael Pont, el 2 de agosto de 1491, mediante la que vende dos suertes de tierras a Rafael Martorell ${ }^{55}$, o las fechadas en Rosas el día 18 de julio del año 1496, por las que dos familias se intercambian sendos documentos con motivo del casamiento de sus respectivos hijos: la viuda de Bartomeu Puig dona parte de los bienes de su marido a su hijo Juan, mientras que Pere Dalmau y su esposa dotan también a Juan Puig 30 libras para que se case con su hija ${ }^{56}$.

En un principio, la escisión entre los diferentes ejemplares que conformaban la misma acción documental se realizaba de forma rectilinea. Posteriormente, y con el fin de dificultar las posibles falsificaciones, se empezaron a cortar de forma sinuosa, bien mediante sistema ondulado o dentado, atendiendo al formato apaisado, rectangular, cuadrado, etc., de la pieza de pergamino.

Con el mismo objetivo, se introdujeron leyendas entre ellos, normalmente de letras mayúsculas, aunque en ocasiones de minúsculas o alternando ambas; raramente símbolos. Lemas muy variados: desde letras del alfabeto hasta palabras o frases, más o menos extensas y de distinto sig-

y su mujer Infante al abad Teoda y al monasterio de los Santos Cosme y Damián de las heredades que poseen en Valdesogo, atesorada en el mismo centro (original $n .^{\circ} 827$ ), en la que el pergamino sobre la que se escribe lleva en el ángulo interior derecho y de forma invertida el inicio de otro documento: "(Christus) In nomine Domini nostri thesu" (J. M. RuIz AsENCIO, Colección documental del Archivo de la Catedral de León (986-1031), vol. III, León, 1987, pp. 91-92).

53 Jesús MUÑoz Y RIVERo lo adelanta hasta la segunda mitad del siglo XI, apuntando que Aragón fue el primer reino de la Península lbérica en que se empleó esta forma de validación. J. MuÑoz y RIVERo, "Cartas partidas: formas y usos", Revista de Archivos, Bibliotecas y Museos, II (1872), pp. 47-48.

${ }_{54}$ M.A. VILAPLANA, La colección dipiomática de Santa Clara de Moguer (1280-1483), Sevilla, 1975 , pp. 37-38. Es el caso de un original del año 1407, el cual posee las circunstancias reseñadas.

55 J. Rosello, Els pergamins de l'Arxiu parroquial de Pollença, Palma de Mallorca, 1985, p. 81. Se atesora en el archivo citado, con el número 82.

56 J. M. MAroués, Pergamins de la mitra (891-1687), Gerona, 1984, p. 139. Ambas se conservan en el Archivo Diocesano de Gerona, la primera con la signatura $C, 24-n^{\circ} 89-$ y la segunda con la C,24 - n 90 - 
nificado. Respecto a la primera fórmula, pueden aparecer sólo algunas letras, iguales o distintas (bien de forma individual -A B C D...-, formando bigramas - AB CD EF GH...-, trigramas - ABC DEF GHI JKL...-, etc.) 0 el vocabulario completo, por lo general a lo largo de todo el corte.

Atendiendo a la segunda técnica, locuciones de todo tipo son empleadas en las leyendas. Así, adernás del término "CIROGRAPHUM", del nombre del autor del documento, del destinatario o de ambos, otras que se incluian eran, por ejemplo: "PLENA DOMINUS TECUM", "CONVENIENCIA CUM FRATRIBUS DE HEREDITATE DE EZQUIOZ", "IN NOMINE PATRIS ET FILII ET SPIRITUS SANCT!», "NEC MUTENTUR PLACET", "NE COMMVTENTUR», "KARTA SANCTE MARIE DE SEBRAIO OBLATE SANCTO VINCENTIO, AMEN", "UT AMPLIUS NON MUTETUR", "DOMNUS DIDACUS EPISCOPUS CUM HEREDIBUS SANCTI TIRSI", "VERBO DOMINI CAELI FIRMATI SUNT ET SPIRITU ORIS EIUS OMNIS VIRTUS EORUM", "HOC CHIROGRAFUM MANEAT FIRMUM, AMEN", "DEUS IUSTVS IVDEX", etc.

En otro orden de cosas, los tipos documentales en los que se incluía esta forma validativa son numerosos, aunque la mayoria de índole sinalagmático: permutas, cartas de foro, cartas de compañia, cartas de arrendamiento, cartas de cesión, avenencias, cartas de quitamiento, ventas, cartas de aprobación, fundaciones, convenios, escrituras de cambio, composiciones, renuncias, cartas de merced, dotes, aceptaciones de testamento, acuerdos, compromisos de defensa, nóminas, testamentos, renuncias, compromisos, pactos, concesiones de fuero, fundaciones, fueros, donaciones, cartas de «subpignoración", pignoraciones, sentencias, reivindicaciones, controversias, nombramientos, testimonios, confirmaciones de conmutación, otorgamientos de beneficio, dejaciones de bienes, particiones de bienes, cartas de reconocimiento de deuda, cesiones, cartas de renuncia, acuerdos, confirmaciones reales, concesiones, trueques, ofrendas, reconocimientos, préstamos, cartas de arras, ofrecimientos, encomiendas, adjudicaciones, demandas, permisos, devoluciones, compras, autorizaciones, conciertos, ratificaciones, etc.*

En una reciente publicación -aparecida en la «Miscelánea de estudios dedicados a la memoria del protesor José Trenchs i Odena"-., la protesora Encarnación Martín López ofrece el porcentaje de tipos documentales en los que esta práctica era utilizada como manera de validación. Así, durante el siglo XII, se empleaba preferentemente en: donaciones (36\%), permutas $(29 \%)$, acuerdos $(18 \%)$, ventas $(9 \%)$ y fueros $(7 \%)$, mientras que en las tres centurias siguientes 10 fue en: arrendamientos $(30 \%)$, permutas $(23 \%)$, donaciones $(21 \%)$, acuerdos $(7 \%)$, ventas $(5 \%)$, préstamos $(3 \%)$ y concesiones (3\%). E. MARTín, "La carta partida como forma de validación", Estudis Castellonencs, 6 (1994-1995), pp. 844-845. 
Documentos, por otra parte, que son empleados tanto en el terreno privado como en el público, siendo sus autores personas de cualquier calidad y condición: monarcas ${ }^{57}$, nobles, eclesiásticos, personas particulares, etc. Del mismo modo, se utilizan en todo el suelo peninsular, pudiendo encontrarlos en Castilla, Andalucía, Galicia, Navarra, Cataluña, Baleares, Valencia, Aragón, etc.

En cuanto a las cartas partidas por A.B.C. del rey Jaime I, contamos con un estudio de la profesora María Josefa Arnall ${ }^{58}$, quien analiza 20 conservadas en el Archivo de la Corona de Aragón (a. 1218-1228). Los temas son variados: confirmación real, permutas, dote, concesiones, etc. A excepción de dos, en los que el corte es ondulado y dentado, en el resto se separan los ejemplares, bien por su extremo inferior o bien por el late$\mathrm{ral}$, de forma rectilinea. En general, la persona autor del hecho jurídico es el rey, aunque en alguna ocasión es a él a quien va dirigido el documento o es testigo del acto. Entre ellas, por su significado, son interesantes: la fechada en Agreda el 6 de febrero de 1221, por la que el monarca entrega a su esposa Leonor, como dote o arras, diversos castillos: Daroca, Pina, Barbastro, Cervera, Tamarite, etc. ${ }^{59}$; el concierto entre Jaime I con fray Gonzalo Yánez, maestre de Calatrava, sobre los pactos y pagos que Pedro II había hecho con Pedro Fernández de Anagra, datado en Zaragoza el 16 de junio de $1224{ }^{60}$; la permuta, fechada en Huesca el 17 de mayo de 1224, entre Jaime I y Miguel de Olso de las villas de Almunia y Lorves ${ }^{61}$; y la confirmación real, del 12 de septiembre de 1225, de la venta de las rentas, por un tiempo de 5 años y mil maravedis, que Guillermo Cervera tiene en diversas villas, a Nicolás Roig y Guillermo de Riufred ${ }^{62}$.

Junto al valor de la escritura, de los testigos y de la estructura específica de las cartas partidas, se introducen, no antes del siglo XIII, otras for-

57 En la documentación real se observa un decaimiento de esta práctica a partir del reinado de Alfonso VIII. Es digna de mención la carta real partida de la escritura de desposorio del infante don Alfonso (más tarde Alfonso X) con doña Violante, cuyo documento comienza así: "Notum sit cunctis, ad quos praesens pagina per alfabetum divisa pervenerit, quod anno Domini MCCXLVI...". J. Muñoz Y Rivero, op. cit, p. 48.

58 M. J. ARNALL, "Las cartas partidas por A.B.C. de Jaime I como "Rex Aragonum, comes Barchinone et dominus Montispesulani", X Congreso de Historia de la Corona de Aragón: Jaime 1 y su época, 3-4-5 (1982), pp. 363-375.

59 Archivo de la Corona de Aragón, n. ${ }^{\circ}$ 187. Publicada por A. Hulcl, Colección diplomática de Jaime 1. Años 1227-1253, Valencia, 1916, n. ${ }^{\circ} 19$.

60 Archivo de la Corona de Aragón, n. ${ }^{\circ}$ 233. Publicado por A. Hutcl, op. cit., n. ${ }^{\circ} 38$.

61 Archivo de la Corona de Aragón, n. ${ }^{\circ}$ 231. Publicado por A. Hulcl, op. cit., n. ${ }^{\circ} 36$.

62 Archivo de la Corona de Aragón, $n .^{\circ} 271$. 
mas de validación que acompañan y refuerzan a las anteriores, como los sellos ${ }^{63}$. Es más, a partir de esta época, en la documentación privada, la validación está constituida por la fórmula notarial de clausura en la que, como expone la profesora Sanz Fuentes, el notario, tras declararse testigo del hecho y haber extendido el documento a ruego de él o de los intervinientes, autentifica el documento notarial, aparecen también, de manera esporádica y siempre como complemento de la fórmula de clausura notarial, otros elementos validatorios; ese es el caso de las cartas partidas o de los sellos ${ }^{64}$.

Para concluir este estudio, queremos referirnos nuevamente a la legislación, en este caso a la hispánica y, en ella, buscar disposiciones relativas a este tema. Como principal característica, se puede anticipar que son pocas las que de una manera directa se refieren a los quirógrafos y cartas partidas.

En el Fuero latino de Teruel, fechado, según se cree, en $1177^{65}$, se establece en sus artículos 92 y 93 que la carta partida por A.B.C., escrita por un notario jurado y firmada por los testigos, hará fe y no se juzgue de ella por otro fuero ${ }^{66}$, salvo el caso de remate de subasta de heredad. En el art. 92, "De iudicio divise carte quod aliud non iudicetur»:

"Et est sciendum quod omni facto et iudicio ubi carta per alphabetum divisa fuerit, et scripta a iurato notario, et firmata testibus, aliud forum non iudicetur, vel transeat, nin quod carta difinierit suo scripto, nisi tantummodo in trançamento hereditatis" ${ }^{67}$

y en el art. 93, «Quod non trançet hereditas»:

"Quia in Turolio nunquam radix aliqua debet trançari, vel etiam fenerari»" ${ }^{88}$.

63 Sirva de ejempio la carta de arrendamiento de la serna de Montecillo de Oca por el abad y monasterio de Oña a don García de Alcocer el año 1268. En ella, además de la disposición material de carta partida - con el corte dentado en su borde superior-, se valida, no sólo con el sello del monasterio, sino con un subsello, en este caso del concejo de Burgos. A.H.N., sec. Clero, carp. 288 , exp. 3.

$64 \mathrm{M} .^{a} \mathrm{~J}$. SANZ FUENTES, "Documento notarial y notariado en la Asturias del siglo XIII", Notariado público y documento privado: de los origenes al siglo XIV, I, pp. 253-254.

${ }_{65}$ Así lo expresan autores como J. CaRuana (El fuero latino de Teruel, Teruel, 1974) y A. M. ${ }^{\text {a }}$ BARRERo (El fuero de Teruel, Madrid, 1979). Sin embargo otros lo atrasan un año, como F. AZNAR (Forum Turolii, Zaragoza, 1905) y algunos lo retrasan a la primera mitad del siglo XIII, como BonILLA Y SAN MARTin ("El derecho aragonés en el siglo XII), Memorias del I/ Congreso de Historia de la Corona de Aragón en Huesca, Huesca, 1922, p. 177) y R. DEL ARCO (La institución del notariado en Aragón, Zaragoza, 1945, p. 11).

66 En lo antiguo, Teruel no se rigió por los fueros de Aragón.

67 J. Caruana, op. cit., p. 114

68 Ibid., pp. 114-115. 
En los artículos 94 y 95 se dispone, por una parte, preceptos sobre los testigos contractuales, a los cuales el notario preguntará si la carta refleja bien lo convenido y, por otra, sanciones a quienes negasen la carta; igualmente, se estipula que si el notario y los testigos hubiesen fallecido, el que la tenga, con ella en la mano, jurará que es verdadera, y será creído. En el art. 94, "Quod in carta divisa testes positi non reptentur et qualiter interrogentur":

"Tamen sciendum est quod firme sive testes qui in carta scripti fuerint non reptentur, et cum cartam negatam forte aliquam firmare debuerint, legendo cartam primitus coram ipsis testibus, et sint coiurati, taliter interrogentur; si fuerunt presentes, et videntes, et etiam audientes, ubi carta illa concessa taliter et mandata fuit facere omnibus concedentibus, iuxta scriptum. Et, si concesserint, compleant; sin autem, non". ${ }^{69}$

y en el art. 95, "De eo qui cartam negaverit quam calumpniam debet pactare":

"Item si quis cartam negaverit et ei cum uno teste et notario, vel cum illis testibus qui in carta scripti fuerint, querelosus illam firmare potuerit, negator pectet peticionem dupplatam et insuper $L X$ solidos, de quibus judex et alcaldes terciam partem habeant, et aliam terciam ille notarius qui cartam scripserit vel firmaverit, et querelosus cum testibus terciam remanentem... Et si forte notarius et testes mortui fuerint, ille qui cartam tenuerit iuret cum uno vicino cartam illam esse veram, tenendo cartam in manibus, et credatur..." 70

En el resto de la legislación consultada, relativa a la Corona de Aragón, hemos localizado pocas disposiciones más directamente relacionadas con estos documentos y su validación. Según su estudio, se da primacía e importancia a la documentación pública y lo que importa, además de los signos, suscripciones y sellos referentes a las personas que poseen fuerza legal documental, es la presencia de los testigos y el reconocimiento de éstos de la veracidad de la acción documentada ${ }^{71}$ :

"... nomem scriptoris debet apponi in carta illa: ut si quis aliquo dixerit aliquid contra cartam, per testes in carta scriptos, et scriptorem si vixerit probetur instrumentum esse verum... Item nullum debitum probatur nisi per cartam publicam... Quicumque fiat donatio haereditatis, cum instrumento publico testibus roborato debet fieri, quia secundum Forum nullus valoris existit donatio sive instrumentum donationis, nisi super ipsa donatione dentur fi-

\footnotetext{
Ibid., p. 115.

ibid., pp. 115-118.

1 Fueros, observancias y actos de Corte del Reino de Aragón, 3 vols., Zaragoza, 1991 (ed. de P. Savall y S. Penen).
} 
dantiae salvitatis, et quod eas contineat instrumentum, exceptis tamen donationibus Regum, Principum et Religiosorum, quae signis, et sigillis cum testibus roborantur..." ${ }^{72}$

"Providendo possibilius quo possumus, ne falsa instrumenta fabricantur. Statuimus et ordinamus, quod notarius quilibet teneatur scribere in principio cuiuslibet instrumenti duas lineas de sua propia manu, et nihilominus testium nomina per literas extensas et calendarium..." 73

"Statuimus de consilio et assensu totius Curiae, quod si de caetero aliquis petierit aliquod debitum, vel comandam vel ostenderit albaranum, diffinimentum, vel aliquam obligationem cum litera aliqua sigillata sigillo alicuius Baronis, vel alterius cuiuscumque quae ab ista die in ante fuerit facta, quae non sit publicum instrumentum, talis petitio non valeat... Aliis vero literis confectis hactenus non intendimus propter huius modi Forum dare autoritatem maiorem quam habere debeant. Et si quis habuerit tales literas temporis praeteriti, non possit petere aliquid de contentis in eis, nisi eas ostenderit, et petierit infra annum a die presenti in antea continue numerandum..., 74

En la Corona de Castilla, uno de los primeros fueros en los que se refiere directamente sobre las cartas partidas es el «Forum Conche», concedido en diciembre de 1189 por Alfonso VIII ${ }^{75}$. En él, en su capítulo X, sobre "El derecho de sucesión de hijos y padres", el apartado 30: "La mujer preñada, tras la muerte de su marido», estipula lo siguiente:

"Si muere el marido sin tener hijos y deja a su mujer preñada, o a su concubina, ella retenga, bajo carta partida por A.B.C., todas las cosas del difunto y de también fiadores de que las guardará sin daño. Si pare antes de los nueve meses, guárdelas para su hijo mientras tanto ella viva de estos mismos bienes".

En el Fuero Real de Alfonso X, otorgado el año $1255^{76}$, no se habla directamente sobre esta forma de validación aunque en los títulos correspondientes a materias afines ${ }^{77}$ se deja constancia de la importancia que adquieren los testigos y los sellos como elementos validativos.

Sin embargo, en el Espéculo ${ }^{78}$ (año 1255), si hay referencias directas a. las cartas partidas. En la ley XXXVI del titulo XII del libro IV, referente a

12 Jaime I. En Huesca, 1247. Ibid., vol. I, pp. 183-184.

73 Martin I. En Zaragoza, 1398. Ibid., vol. I, p. 184.

74 Jaime II. En Daroca, 1311. Ibid., vol. I, p. 186.

75 El Fuero de Cuenca, 2. ${ }^{a}$ ed., Cuenca, 1978, p. 15 (intr. y trad. A. Valmaña).

76 Fuero Real del rey don Alfonso el Sabio, Valladolid, 1979. Reproducción facsímil de la edición de Madrid (Imprenta Real, 1836), copiado del códice del Escorial, señalado ij.z.-8, y cotejado con varios códices de diterentes archivos por la Real Academia de la Historia.

77 Libro I, título VIII: "De los escribanos públicos" y libro II, título IX: "De las cartas e de los traslados". DiEZ).

78 Leyes de Alfonso X. I: Espéculo, Ávila, 1985 (edición y análisis crítico de G. Martinez 
"los escribanos", se exige con relación a los trueques o cambios que se hagan

"dos cartas partidas por abeçe, amas de una manera, e amas deven dezir commo ffueron ffechas ende tales dos cartas, e deve tener el uno la una e el otro la otra. E dessi deve y dezir el día e el mes e el era e los testigos ssegunt dixiemos en la ley ante désta... E después deven y escrivir ssus nonbres con ssus manos missmas los testigos que y ffueren llamados sennaladamiente por aquella vendida, e al menos deven sser a tales que entiendan la carta e la sepan leer. E otrossi el escribano de conçeio que escrivier la carta deve $y$ escrivir ssu nonbre e ffaser y ssu ssennal connosçida en cabo de toda la escriptura, e que ssea commo ençerramiento de todo lo al. E la carta que desta guisa ffuere escripta, sserá ffecha derechamiente..." 79

Como se puede comprobar, la fuerza validativa residía principalmente en los testigos y en el escribano, y en sus respectivas suscripciones y signos. En el resto de las leyes de este título y del VI: "de las querellas e de las cartas", se reglamenta la forma en que deben realizarse los diferentes tipos de cartas, tanto públicas como privadas, quedando de manifiesto lo fundamental que eran los elementos citados anteriormente, junto con el sello ${ }^{80}$, para que tuvieran valor.

Al igual que en el Espéculo, en Las Siete Partidas o Libro de las Leyes ${ }^{81}$, que constituyen el código más importante de toda la Edad Media y la más amplia recopilación legislativa llevada a cabo desde los tiempos de los grandes jurisconsultos romanos y que, según afirma el mismo rey, comenzó su tarea en Sevilla en 1251 y le ayudó una comisión de juristas compuesta, principalmente, por el maestro Jacobo Ruiz, el notario de León Juan Alfonso, el maestro Roldán y Fernando Martínez, se hace mención de los quirógrafos, volviendo a reiterarse constantemente la importancia que adquieren los elementos ya expuestos como validativos de la documentación ${ }^{82}$. Tres objetivos se propuso el rey Sabio: 1) llevar a cabo la gran recopilación y reforma jurídica deseada por San Fernando; 2) ayudar y dirigir a los juristas y a los monarcas que reinasen después; y 3) dar los medios a sus súbditos para que conociesen el derecho y la razón. Representan un vastísimo conjunto de normas para regular las más diver-

79 Ibid., pp. 384-385.

80 Ver libro IV, título XIII: “De los sseelladores e qué cosas deven ffazer e guardar».

a) Las Siete Partidas, 3 vols., Madrid, 1974.

82 Ver Partida III, título XVIII, "De las escrituras, porque se prueban los pleytos"; Partida III, título XIX, "De los escrivanos, e quantas maneras son dellos, e que pro nace de su oficio"; Partida III, título XX, "De los sellos e de los selladores de la chancilleria"; y Partida VI, título I, "De los testamentos". 
sas acciones humanas y las relaciones entre sí de los individuos y de las clases, pero no entran en vigor hasta 1348, reinando Alfonso XI. Es en la ley CXIIII, del título XVIII de la III Partida: "En que manera las cartas deven valer non aviendo en ellas algunas de las falsedades, o menguas que de suso son dichas", en donde se declara:

"...Aun dezimos que si alguno faze carta por su mano, o la mando fazer a otro que sea contra si mismo, o pone en ella su sello que puedan provar contra el por aquella carta si la demanda fuere por razon de aquel mismo que fizo la carta, o la mando fazer assi como de emprestido que demanden de pan, o dineros o de otro mueble que se pueda contar, o pesar, o medir. Pero si aquel cuyo fuesse el nome que fue escrito en la carta lo negare non deve ser creyda contra el amenos que la otra parte prueve que el la fizo, o por su mandado fue fecha. Mas si tal carta fue fecha sobre cosa sennalada assi como sobre vendida, o cambio de casa o de viña, o de otra tal cosa non vale para provar con ella, cumplidamente como quier que faga alguna presuncion. E esto es porque las cartas de tales pleytos deven ser fechas por manos de escrivanos publicos, o de otros seyendo firmadas por buenos testigos porque falsedad nin enganno non pueda ser fecho en ellas..."

Asimismo, en la ley CXIX del mismo título: "Quales son las otras maneras de pruevas que usan los omes en juyzio para provar sus entenciones" ${ }^{83}$, se expresa que:

"Ca non tan solamente quiere provar por testigos, e por cartas publicas, mas aun por otras que son fechas por mano de otros omes que non son escrivanos publicos, e por ende dezimos, que si alguna de las partes aduxesse alguna carta en juyzio que fuesse fecha por mano de aquel contra quien faze la demanda, o de otro que la oviesse fecha por su mandado, si la postura, o el otorgamiento que esta escrito en ella es con razon diziendo assi que fulan deve a fulan tantos maravedis que el empresto, o quel encomendo, o que los devia por otra guisada razon qualquier, si la perte contra quien aduzen tal carta como esta la otorgare, deve valer bien assi como si fuesse fecha por mano del escrivano publico. Mas si la negare diziendo que non la fizo nin la mando fazer. E aquel que se quisiere a provechar della dize que si: e que quiere estar en esta razon por su jura, entonce es tenuda ala parte de jurar si la fizo, o la mando fazer, o non. E si por aventura non le demandasse esta jura, mas dixesse que lo queria provar en esta manera mostrando otra carta que es verdaderamente escripta por mano de aquel mismo que es semejante en todo en la letra, e en la forma de aquella que el muestra contra el en tal caso como este dezimos que non deve ser creydo fueras ende si pudiere provar por dos testigos buenos sin sospecha que el otro fizo aquella carta, o la mando escrevir. Otrosi dezimos que si alguna de las par-

в3 En la ley anterior se estipulaba el peritaje como prueba para cotejar la documentación. Ibid., vol. II, fol. 120. 
tes aduxere en juyzio alguna carta por provar su intencion que non sea fecha por mano de escrivano publico si la otra parte queriendole desechar muestra otra carta fecha por mano de aquel mismo ome que es de semejante en todo a la primera en la letra, e en la forma si aquel que aduze la carta para provar con ella su intencion provare con dos testigos buenos, e sin sospecha que juren, e digan que vieron aquel cuyo nombre esta escripto en ella fazer aquella carta, o mandarla escrevir: dezimos que provandolo assi deve ser creyda maguer la otra parte mostrasse otra carta escripta por mano de aquel mismo ome que fuesse de semejante della en todo en la letra, e en la forma"

Interesante es también la ley XII del título I de la sexta partida: "En que cosa puede ser escrito el testamento", en la que se refiere a los originales múltiples de la siguiente manera:

"En pergamino de cuero, o de papel, o en tablas, quier sean con cera, o de otra manera, o en otra cosa en que se pueda fazer escritura, e parescer, puede ser escrito el testamento. E aun dezimos que de un testamento, puede ome fazer muchas cartas de un tenor. E destas cartas puede el testador levar la una consigo, e las otras puede poner en algund logar seguro, assi como en sacristania de alguna eglesia, o en guarda de algund su amigo. $E$ estas cartas deven ser fechas en una manera, selladas de unos sellos mismos, e de tantos la una como la otra, de guisa que acuerden las unas con las otras. Pero si alguna dellas fuere menguada, non empece a las otras que fuessen cumplidas".

Por último, en la ley XIII del título I de la misma partida: "Quien puede fazer testamento e quien non", se legisla lo siguiente:

"... el que es mudo, o sordo desde su nascencia, non puede fazer testamento. Empero el que lo fuesse por alguna ocasion, assi como por enfermedad, o de otra manera, este a tal si supiesse escrivir, puede fazer testamento, escriviendolo por su mano misma..."

Mientras que si fuese un invidente deberia tener delante siete testigos y un escribano para que tuviese valor su testamento ${ }^{84}$.

\section{CONCLUSIONES}

Como principales conclusiones de todo lo expuesto anteriormente, se pueden establecer las siguientes:

${ }^{84}$ Ley XIIII, título I, VI partida, "En que manera el que fuere ciego puede fazer testamento". lbid., vol. III, fol. 6 . 
1) Los quirógrafos derivan de ciertos testimonios antiguos, utilizados ya por los griegos y romanos, en los que su propia escritura (autografía) constituía una prueba de legitimidad. La fuerza probatoria residia en la escritura autógrafa, no en los testigos, ya que sólo tenían validez en textos escritos y casos particulares.

2) En el siglo III aparecen una serie de documentos, derivados de los anteriores y similares en su forma, con el calificativo de "chirographos". La fuerza probatoria de éstos seguía estribando en la autografía, pero sólo adquirían valor pleno cuando los testigos lo confirmaban, ya que no eran los propios interesados, necesariamente, los encargados de escribirlos. El documento testimonial romano antiguo, carente de sello, se fusiona con el quirógrafo al incorporarse la firma de la persona que se obligaba.

3) Desde el siglo III, el viejo Derecho Romano otorga validez a cartas de contenido dispositivo, por lo que la forma de los documentos quirografiados era apropiada para esta finalidad: la expresión de una decisión o mandato. Sin embargo, hasta el siglo XI, el término "quirographum" fue genérico; más tarde va cambiando de significado, hasta restringirse, de modo que llegó a entenderse por tal, aquel documento de formato especial redactado con duplicación de texto sobre un mismo folio de pergamino, que se valida con una divisa o lema común colocado en la mitad del pergamino o papel para separar los distintos instrumentos escriturarios. Esta disposición especial se produce para escribir originales múltiples sobre un mismo folio, limitándose, inicialmente, a los documentos (escritos) múltiples.

4) Suele señalarse como lugar de origen de estas "cartas partidas" el territorio anglosajón entre los siglos VIII-IX, pasando de las Islas Británicas al continente en la centuria siguiente. Mediante las "cartas partidas" se redactaron numerosas actas y contratos de todo tipo, especialmente de carácter sinalagmático. Su uso en toda Europa se generaliza en el siglo XII, si bien en el siglo XV se emplean bastante menos, conservándose ejemplares, al menos, hasta finales de la centuria XVIII.

5) Por lo que se refiere a la Península Ibérica, las características que adopta este sistema de validación se asemejan bastante al empleado en el resto de Europa. Tras la caida del Imperio Romano y de su dominio en la Península, la presencia de la documentación quirografiada sigue siendo patente, si bien aquí su fe y credibilidad estaba basada en la identificación de la letra y en la presencia de los testigos.

Junto a la "escritura", medio de prueba tradicional, se emplearon otras modalidades comprobativas, como las "cartas partidas", que si bien aparecen a finales del siglo $x$, no se hacen frecuentes hasta la centuria XII. 
Entre nosotros, el declive de las "cartas partidas" empieza a finales del siglo XIII, período áureo no sólo del valor y utilización del sello sino también de la multiplicación del documento notarial auténtico, aunque su uso llega, como mínimo, hasta finales del siglo xv. De ahí que, sin perder valor la escritura personal y autógrafa en sentido parcial (firmas) y exigiéndose la presencia de los testigos, las "cartas partidas" para que alcancen la máxima credibilidad y validez deban reforzarse con la aposición del sello o sellos, tanto de autoridades como de oficiales y particulares.

\section{APÉNDICE DOCUMENTAL E ILUSTRACIONES}

1. El diácono Vicente otorga testamento a favor del abad Victorián y del monasterio de Asán. Asán, 29 de septiembre de 551. “Biblia Oscense», fol. 1, Biblioteca del Museo Arqueológico Nacional de Madrid.

"Domno sancto hac beatissimo et mihi speciali domino Victoriano abbati, Vincentius diaconus. Sancti nos Evangelii vox admonet dicens: nisi quis renunciaverit omnibus que possidet meus discipulus esse non potest. Quod credentium multitudo in exordio predicationis apostolice, prediis suis venditis, adimplentes, precio omni adgretato, apostolis deferebant arbitrio illorum prout cuique opus erat dispensandum, quibus animas suas ob desiderium eterne vite attulerant conservadas. Quam devotionem ego [prem]onitus intuens eo tempore si facultas permisisset facere debui, cum ad servicium Dei, ipso miserante atque inspirante, accessi. Nunc autem quando Domino placuit ut de paupertatula parentum ad meum dominium aliqua pervenirent, in toto devotionis affectu decrevi quod semper apud animi mei arbitrium deliberatum habui ut in usus pauperum ad quantum vires admittunt ea conferam dividenda, credens quod sim a Domino peccatorum veniam percepturus si servorum illius fida oratione ipsi fuero assidue commendatus. Propterea sancto monasterio Asani ubi me Dominus a pueritia mea vestra eruditione nutrivit, prona voluntate nec ullo cogenti imperio dono ac donasse me profiteor. In terra Terrantonensi in locum Scenoise porcionem meam, asserisse porcionem meam, Evelaiti porcionem meam, asanustui porcionem meam,... porcionem meam. In terra Barbotana Arcaraimo porcionem meam, sub monte Polenario cum Meariano porcionem meam. In terra Labetolosano Calasanci porcionem meam, cum eleceto Borgisali porcionem meam, Abditinne porcionem, Berce porcionem meam, Maremortuum porcionem meam, Petroroveida porcionem meam. In terra Hilardensi Paternianico porcionem meam, Cercomagno porcionem meam, ad domum Eulali porcionem meam, Semproniano porcionem meam, ad domum Retiari porcionem meam, Lacunarupta porcionem meam, Anduso porcionem meam, Ausevero porcionem meam ex integro, ita ut in monasterium Lobe, si ipsi iusseritis, debeat deservire. In terra Boletano Senguanis porcionem meam, Isusti porcionem meam, estiva Saldana porcionem meam vel alias estivolas ubi me procio contingit. In terra Cesaraugustana Adhoce porcionem meam, Intrigario porcionem meam. Hec igitur loca cum edificiis terris vineis, oleis, ortis, pratis, pascuis, aquis aquarumve, ductibus, aditibus, acessibus, colonis vel servis atque omni iure suo peculio vero omnium vaccarum vel equorum greges que ed meum dominium pertinent vobis beatis- 
sime pater vel huic sancte congregationi, ubi me Dominus vocare dignatus est, per hunc donationis textum confero. Quod precor omne suscipiatis et pro mea stabilitate indesinente orere volueritis fusa obsecratione deposco ut ipse imbecillitatem meam adiuvet, ipse gratiam suam augmentare faciat, ipse quod in me incoavit in bono perficiat, cuius et vocationem hactenus adeptus sum. Aliqua loca que in hac paginula non nominavi pro quarta parte hereditatis iuxfa legum decreta resonant. De hiis vero que pro obsequio vel servitutem vel ingenuitatem vel munuscula prevenerunt, nec mihi parvitatem reservo. Ita igitur quod omnia vel huius donationis cartula vestra fuerunt un dies vite mee quod pro traditione legibus constat, ubertim probavit. Quod habendi tenendi et possidendi et domui sancti monasterii in perpetuum vindicandi ex mea largitate liberalitatis arbitrium, qui solet esse Deo gratum, hoc semper intra animi vero secreta et desiderantis ardore deliberatum [est], quod nunc adiuvante Deo a me est prolatum. Hoc ergo rememorandum putavi un nullatenus per ven[dicationem ault alliam acltionem a iure monasterii quod pro affectu contuli [retraha]tur. luro autem per Deum omnipotentem et futuri iudicii examinationem me huius liberalitatis vinculum inviolabiliter custoditurum, neque per quemquam heredum meorum arbitror retinendum. Si quis sane, quod fieri non credo, immemor extremi iudicii temerator huius facti quolibet existere voluerit, primitus a sacrosanctis ecclesie liminibus arceatur auctoritate omnium sacerdotum anathematizandus, demum iudicio Dei sicut Datan et Abiron vivus terre hiatibus absorbeatur, lude quoque proditoris Domini subiturus sententiam vel Ananie vel Safire quos districtissima severitate in presenti etiam seculo legimus esse dampnatos, beatidudini vero vestre inferre cogatur estimate vel meliorate quantumcumque rei ipsius duplam precii quantitatem, manente nichilominus inviolabili firmitate, cui dolus malus abest afuturusve est. Stipulans itaque stipulatus sum et spopondi Aquiliae legis mentione subnixa que scripturis omnibus solidum prestat robur. Quam cartulam manu mea propria scripsi, cui si gesta aut testes forsitan adhibiti non fuerint ologrife manus mee ad integrum conscriptio pro omni firmitate subsistit.

Facta cartula in monasterio Asani sub die $11^{\circ}$ kalendas actobris anno $11^{\circ}$ domini nostri Agile regis.

Vincentius in Christi nomine diaconus hanc cartulam donationis quam feci propria manu signavi, relegi et subscripsi"»

2. Alfonso Il de Aragón dona a Pedro de Riart la bailia de San Martín de Castelar. 9 de septiembre de 1165. A.C.A., pergaminos de Alfonso 1 de Cataluña, n. 25.

\section{«ABCDEFGHIJKLMNOPQR}

Sit notum omnibus hominibus quod ego lldefonsus Dei gratia rex Aragonum et comes Barchinone, assensu et consilio Guillelmi episcopi Barchinone et Arnaldi Mironis comitis de Palars et Guillelmi Raimundi dapiferi atque Raimundi de Gerundela et tocius curie meae dono et concedo tibi Pedro de Riart illam meam baiuliam Sancti Martini de Castelar sicut melius unquam dominus Comes pater meus eam tibi donavit et prout melius eam habuisti et tenuisti. Tali modo istam baiuliam tibi dono, ut de omnibus expletis que Deus ibi dederit panis videlicet et vini, dones mihi per unumquemque annum VI quartas de blaa ad mensuram comitalem et hoc non possit minui et quod sis inde mihi bonus atque fidelis in omnibus. Propter hoc autem donum quod facio tibi iam dicto Petro accipio a te $L$ denariorum solidos quod est manifestum. Actum est hoc $V$ idus septembris anno Domini millesimo CLXV. 
Un sistema de validación documental: de la Quirografía a las cartas partidas

Signum Ilde(signo)fonsi regis Aragonum et comitis Barchinone. S(signo)ignum Guillelmi Raimundi dapiferi. Sig(signo)num Bernardi Bovis.

Poncius de Osore scriba domini regis scripsit hoc et fecit hoc sig(signo)num"

3. Carta de arrendamiento de la serna de Montecillo de Oca por el abad y Monasterio de Oña a don García de Alcocer. [Oña], 13 de enero de 1268. A.H.N., sec. Clero, carp. 288, n. $^{\circ} 3$.

«ABCDE.

Conoscuda cosa sea a todos los que esta carta vieren, que nos don Peydro Perez, por la gracia de dios abbat de Onna, e nos conviento des mismo logar, arrendamos a vos don Garcia de Alcoçer la nuestra serna que dizen de Monteziello de Occa por tal pleyt vos la arrendamos por en toda vuestra vida, que nos dedes cadanno I maravedi por renta, por la fiesta de San Martin e que non ayades poder de venderla ni de empennarla nin de meterla so otro sennorio, si non que por esso la perdades, e depues que vos finartes que finque libre e quita al monesterio de Onna la sobredicha serna. $E$ desto fazemos dos cartas partidas por a.b.c., e tiene la una el sobredicho don Garcia e la otra tenemos nos en el monesterio. E porque est pleyt sea firme nos don Pero Perez, por la gracia de dios abbat de Onna, e nos conviento des mismo logar, mandamos sellar estas cartas con nuestros sellos. E yo don Garcia el sobredicho, otorgo esto que esta en esta carta de lo cumplir e de lo tener, e porque yo sello non avra, ruego al conceiio de Burgos que manden poner el sosello en esta carta. E nos conceiio de Burgos por ruego de don Garcia el sobredicho nuestro vezino mandamos poner nuestro sello en esta carta en testimonio. Facta carta in mense ianuarii, era MCCCVP, idus ianuarii».

4. Quirógrafo del pontífice Clemente XIV a monseñor Garampi, prefecto del archivo italiano, sobre la correspondencia mantenida por Felipe $\mathrm{N}$, rey de España, y sor María de Jesús, religiosa del convento de Agreda. Roma, 26 de julio de 1769. Arch. Vat., A.A. Arm. I-XVIII, 3777.

“Monsignor Giuseppe Garampi, prefetto dei nostri archivi segreti. Vi comandiamo di estrarre dal nostro archivio di Castel S. Angelo, e precisamente dalla capsula XI dell'armario XIII, una scatola contenente il ritratto di suor Maria d'Agreda, e un di lei libretto con titolo "Relacion que la Ven. madre sor Maria de Jesus, religiosa del convento de Agreda, hizo y escrivio de su letra del estado y progreso de su vida, etc.", che si crede scritto originalmente di suo pugno, e che fu spedito alla santa memoria di Benedetto XIV nostro predecessore da Gio. Battista de Yarza, come da sua lettera in data di Madrid 7 settembre 1748 in detta medesima scatola esistente, insieme colla minuta della risposta fattagli dal medesimo nostro predecesore dei 7 agosto 1748, siccome anche una lettera originale di Filippo IV re di Spagna alla detta serva di Dio dei 16 maggio 1656, e la ed estratte che avrete tutte le cose suddette, vi commettiamo di consegnarle a monsignor Carlo Alessio Pisani promotore della fede, dal quale ne ritirerete ricevuta nelle forme consuete. $E$ col presente nostro chirografo, il quale vogliamo che colla sola nostra sottoscrizione abbia tutto il valore, ancorché non presentado né registrato, vi liberiamo del render conto di detta scatola e lettere, perché questa è la volontà nostra. 

$X I V \cdots$.

Dato sal nostro palazzo apostolico Quirinale, questi di 27 luglio 1769. Clemens papa

5. Ermesinda, viuda de Guillermo Olivar, dona a Pedro de Palacio, su señor, los feudos y derechos que le correspondian vinculados al castillo (castro) de Tallada, reservándose el usufructo de los mismos hasta el final de sus dias. 13 de junio de 1182. Archivo de la Casa Ducal de Medinaceli (Sevilla), sec. Ampurias, leg. 8, exp. 697.

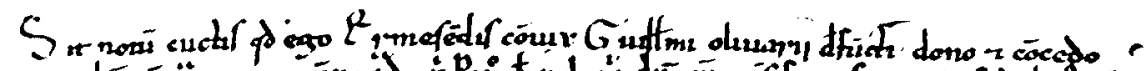

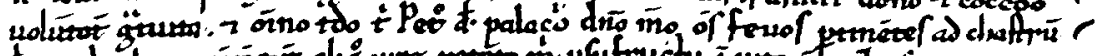

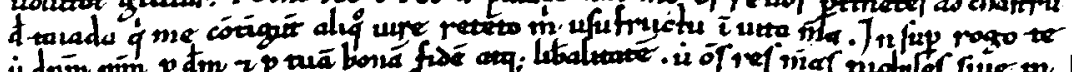

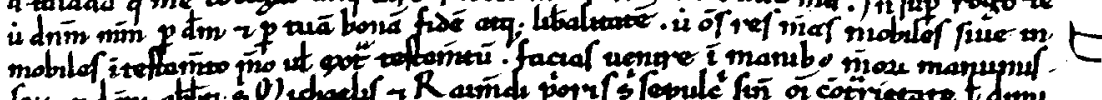

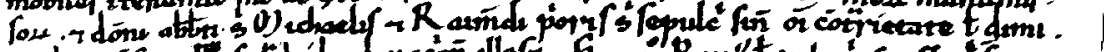

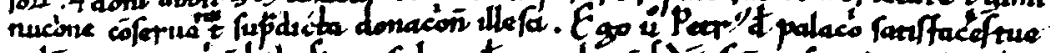

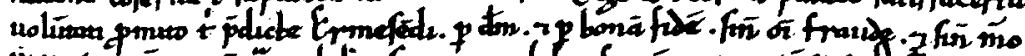

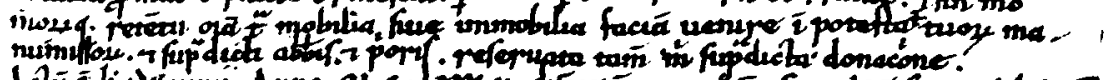

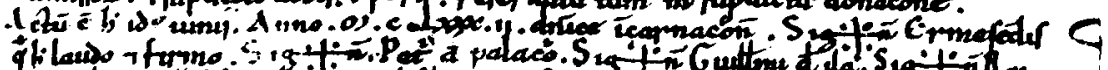

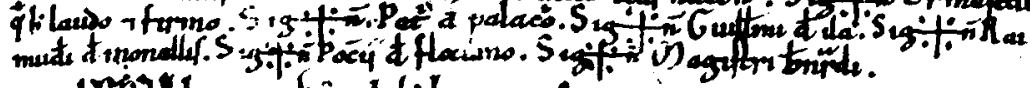

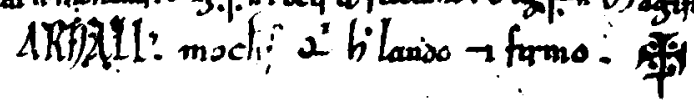

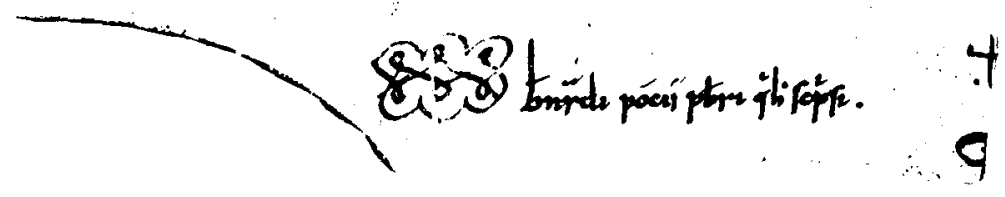


6. Privilegio de Alfonso VIII de Castilla por el que concede a la catedral de Ávila las heredades que tuvo en vida Fruchel, maestro de obras de la misma, a cambio de unas heredades en Toledo, compradas a Tello Pérez de Meneses. Toledo, 12 de febrero de 1192. A.H.N., sec. Clero, carp. 19, n. $^{\circ} 4$.

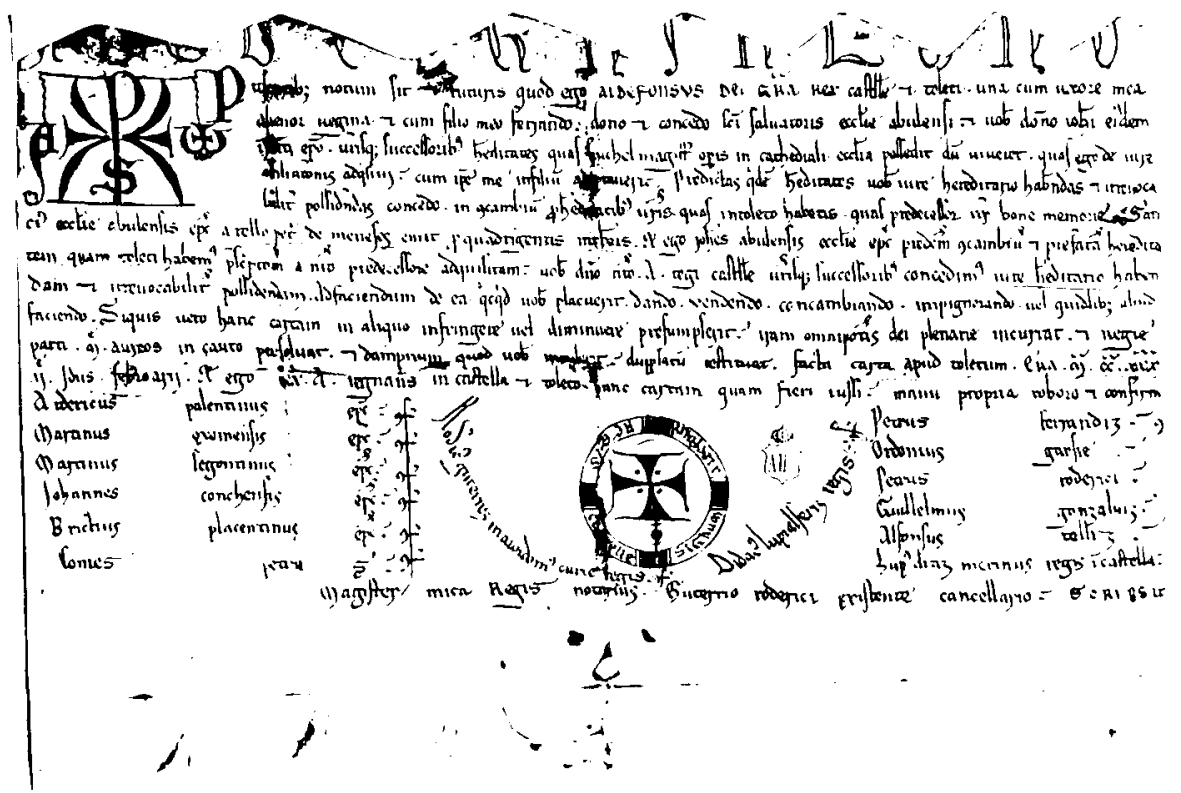


7. Don Pedro, abad de Oña, dona a Pedro Miguel de Arce y a su mujer, Marina Pérez, la iglesia de Tulles. 1202. A.H.N., sec. Clero, carp. 280, n. $^{\circ} 5$.

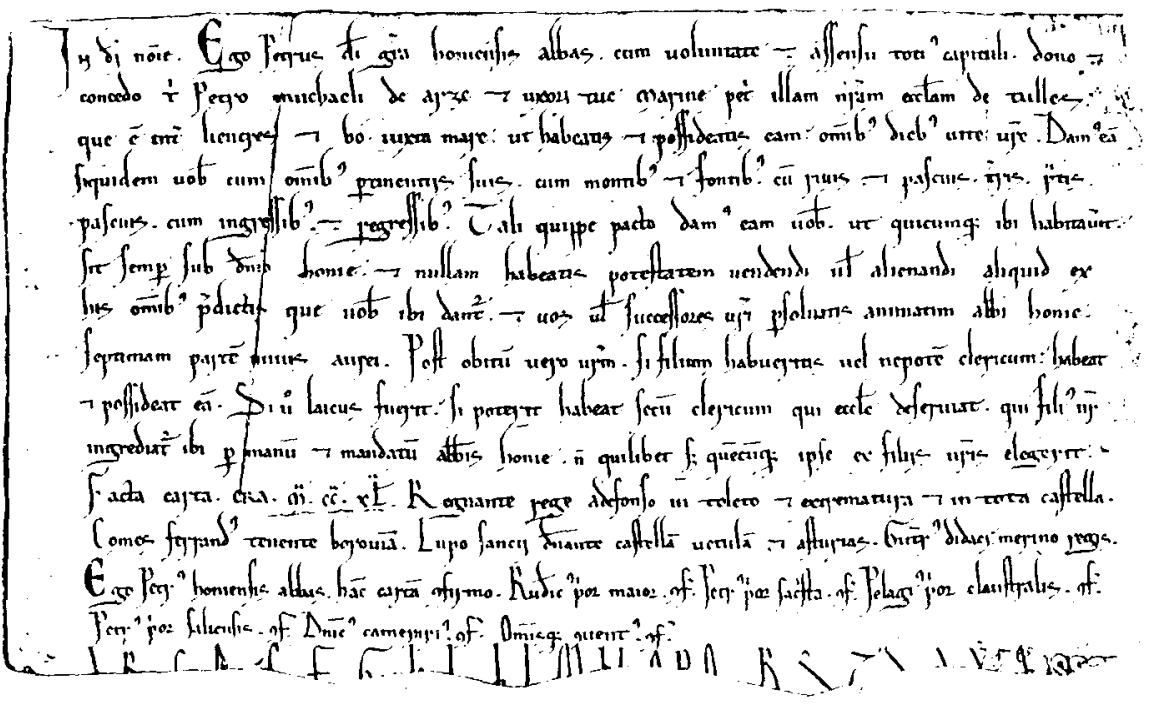


8. La abadesa Margarita y la comunidad conventual de Monstier-surSambre, adscrita al priorato de Basse-Wavre, acensa una tierra-cortina de su propiedad, sita en Villa de Frankeneis, a la iglesia de Santa Maria de Wavera. 1213. Ch. Reusens, Eléments de Páleographie, Louvain, 1899, p. 262.

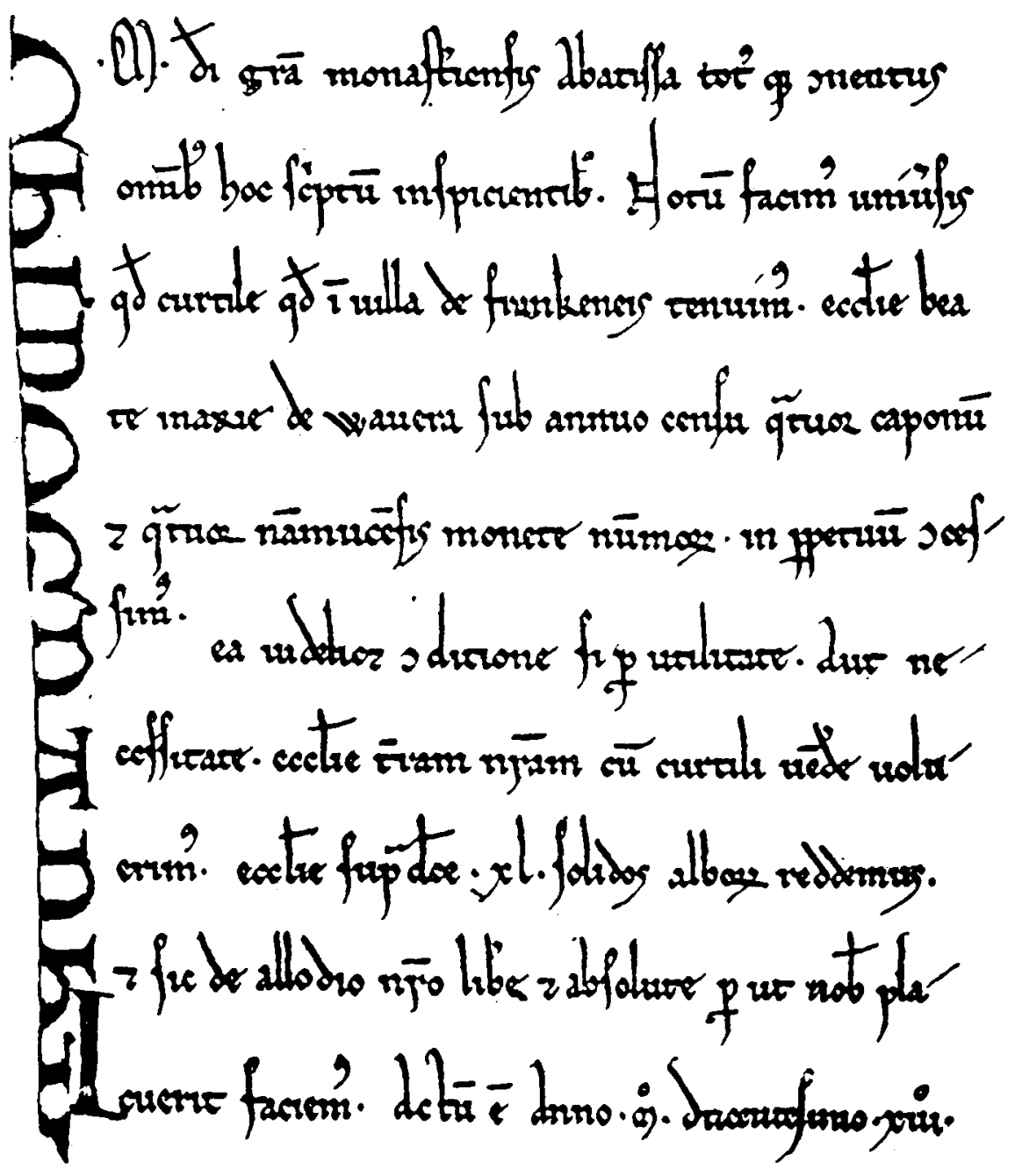


9. Don Garcia, abad de San Salvador de Leire, confirma a los colonos de Ororbia el fuero que habian tenido hasta tiempos de Pedro de Sarasa. Mayo, 1219. A.H.N., sec. Clero, carp. 1406, n. ${ }^{\circ} 17$.

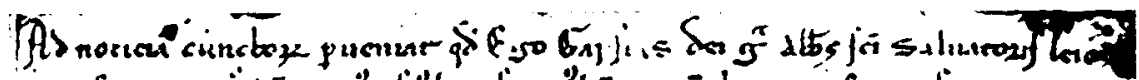

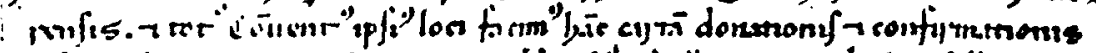

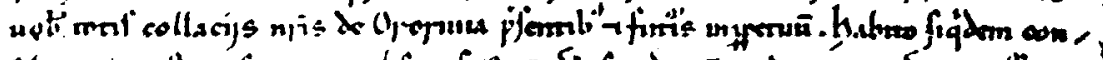

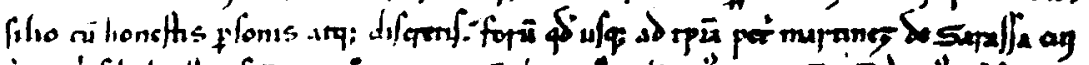

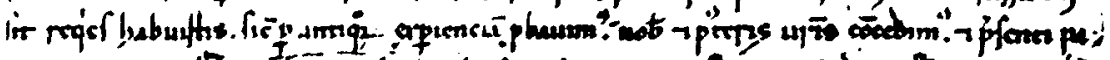

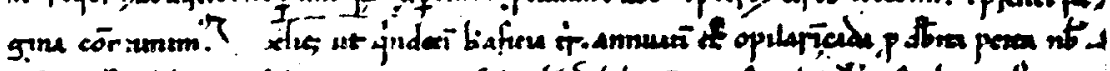

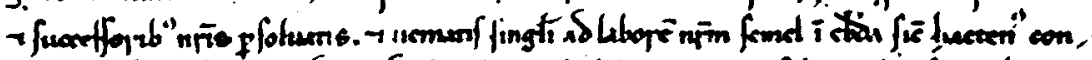

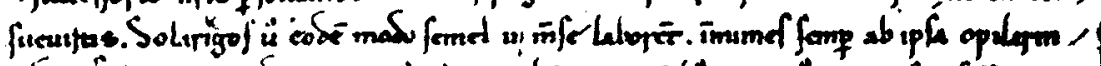

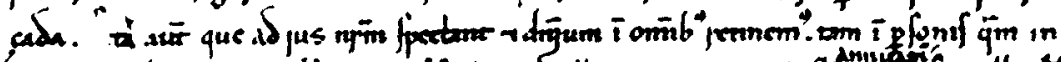

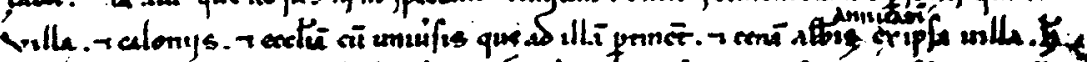

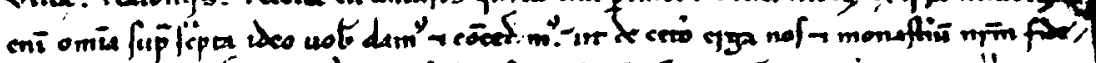

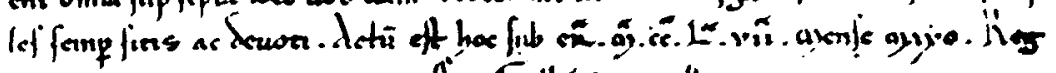

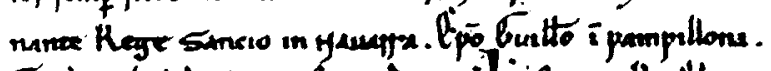

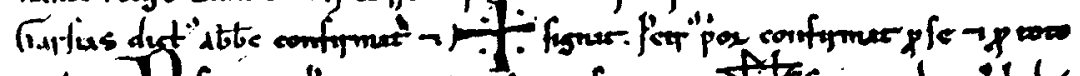

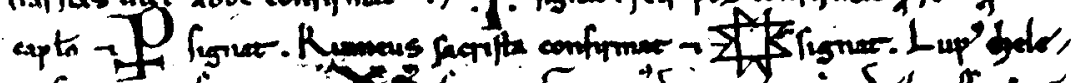

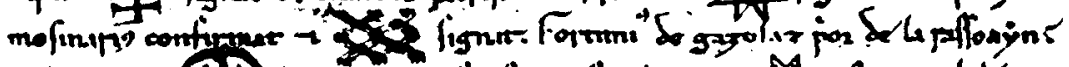

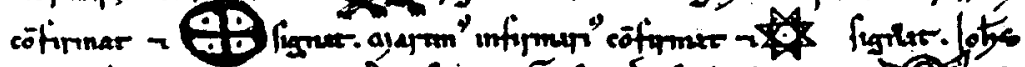

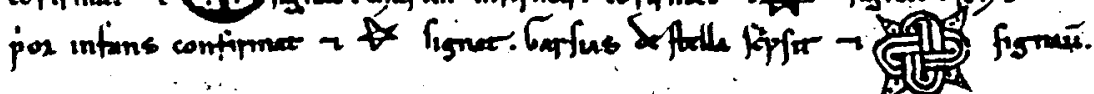

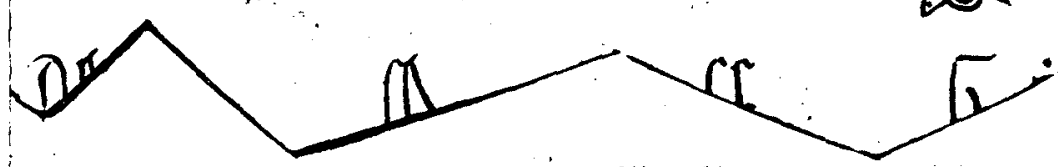


10. Juramento vasallático con promesa de ayuda, fidelidad y defensa del vizconde Gofredo de Rocaberti al conde Hugo de Ampurias por permitirle construir en término de Cabanes un castillo, bajo esta denominación, con sus torres y fortalezas. 28 de mayo de 1271. A.D.M. (Sevilla), sec. Ampurias, leg. 6, exp. 546.

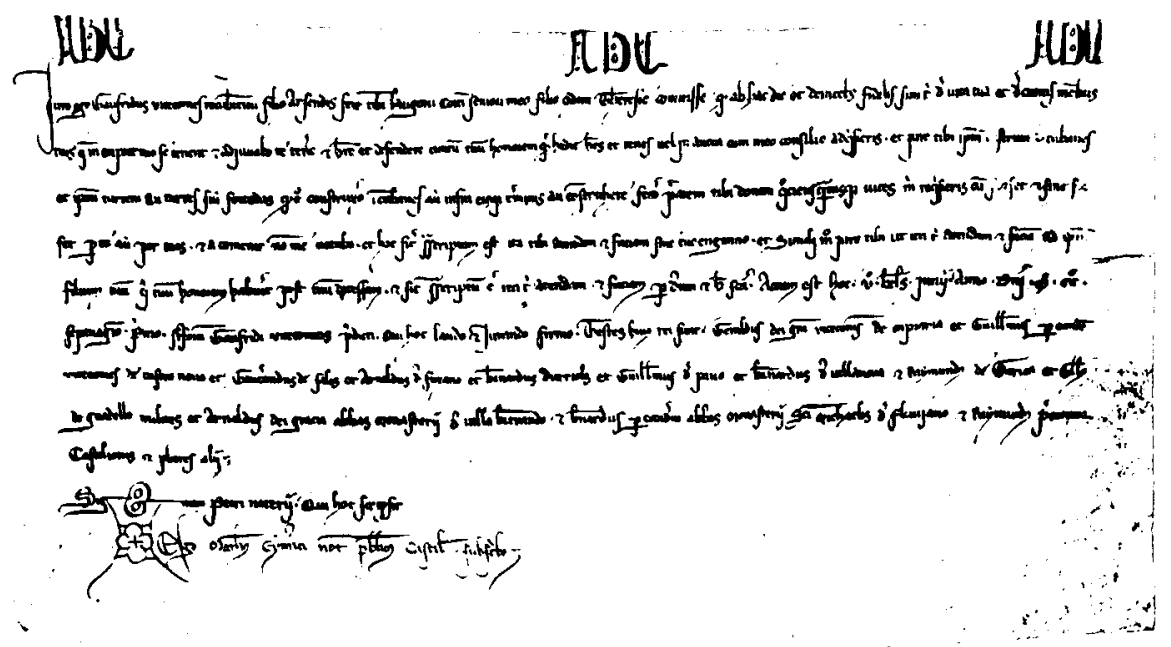

